\title{
Systematic identification method for data analysis and phase equilibria modelling for lipids systems
}

Perederic, Olivia A.; Cunico, Larissa P.; Kalakul, Sawitree; Sarup, Bent; Woodley, John M.; Kontogeorgis, Georgios M.; Gani, Rafiqul

Published in:

Journal of Chemical Thermodynamics

Link to article, DOI:

10.1016/j.jct.2018.02.007

Publication date:

2018

Document Version

Peer reviewed version

Link back to DTU Orbit

Citation $(A P A)$ :

Perederic, O. A., Cunico, L. P., Kalakul, S., Sarup, B., Woodley, J. M., Kontogeorgis, G. M., \& Gani, R. (2018). Systematic identification method for data analysis and phase equilibria modelling for lipids systems. Journal of Chemical Thermodynamics, 121, 153-169. https://doi.org/10.1016/j.jct.2018.02.007

\section{General rights}

Copyright and moral rights for the publications made accessible in the public portal are retained by the authors and/or other copyright owners and it is a condition of accessing publications that users recognise and abide by the legal requirements associated with these rights.

- Users may download and print one copy of any publication from the public portal for the purpose of private study or research.

- You may not further distribute the material or use it for any profit-making activity or commercial gain

- You may freely distribute the URL identifying the publication in the public portal 


\title{
Systematic Identification Method for Data Analysis
}

\section{and Phase Equilibria Modelling for Lipids Systems}

Olivia A. Perederic ${ }^{a}$ Larissa P. Cunico $^{a}$, Sawitree Kalakul ${ }^{a}$, Bent Sarup ${ }^{b}$, John M. Woodley ${ }^{a}$, Georgios M. Kontogeorgis ${ }^{* a}$, Rafiqul Gani ${ }^{a, c}$

${ }^{a}$ Department of Chemical and Biochemical Engineering, Technical University of Denmark, DK2800 Kgs. Lyngby, Denmark,

${ }^{\mathrm{b}}$ Vegetable Oil Technology Business Unit, Alfa Laval Copenhagen A/S, DK-2860 Søborg, Denmark

${ }^{c}$ PSE for SPEED, Skyttemosen 6, DK-3450 Allerod, Denmark

\begin{abstract}
Industrial use of lipids has been increasing as a consequence of increased developments related to bio-based economies. In addition to applications in food-products, lipids are used by many industrial sectors, for example, biodiesel, edible oil, health, and personal care. Phase equilibria predictions for chemical systems with lipids play a major role in process-product modelling, simulation and design. Due to the large number of lipid-compounds involved, predictive methods like group contribution based methods are particularly suitable for estimation of pure compound and mixture properties that may not be available. Limited experimental data availability and poor performances of currently available group contribution based methods is therefore an obstacle for obtaining the necessary information regarding phase equilibria of chemical systems with lipids. In this paper, a systematic identification-regression method (to be called identification method) for phase equilibrium modelling, where, based on the available experimentally measured phase equilibrium data, the selected model parameters are estimated in a hierarchical and efficient manner, is presented. The aim of the method is to improve the quality of phase equilibria prediction for the selected group contribution based methods. By applying the
\end{abstract}


identification method, a new set of binary group interaction parameters regressed from vapourliquid equilibrium data for chemical systems with lipids is presented for the Original UNIFAC model, together with regression statistics and model performance. An extended and updated version of the in-house SPEED Lipids database, which is used for the needed pure compound properties and phase equilibria data, is also presented.

\section{INTRODUCTION}

Lipids, also known as fats and oils, are organic compounds of biological origin which are belonging to different classes such as: fatty acids, fatty esters, mono-, di- and triglycerides, sterols, waxes, etc.[1]. In this paper lipids refer to all compounds that are usually found in vegetable oils and fats. Also, chemical systems with lipids are simply referred to us as "lipids". In recent years, use of lipids has started to shift towards the bio-industry making them important renewable materials for the future chemical and other related industries, and leading to oils and fats industry expansion along with a scale reorientation from local to large-scale industry [2]. In the last 25 years the use of lipids has almost doubled, reaching a capacity of 212 million tons in 2016/2017 [2], an important contribution being made by the increasing demand for biofuels. The evolution in fats and oils consumption from 1989 to 2017 is presented in Figure 1, where it can be noted that the biofuel industry covers almost $15 \%$ out of the total lipids consumption in $2016 / 2017$, while the remaining $85 \%$ is represented by food and other industries like cosmetics, paintings, and base chemicals production [2, 3].

[insert Figure 1 here] [4]

Lipids-based industries employs processes such as, fat splitting, esterification, epoxidation, hydrogenation, amidation, sulfonation, and ethoxilation [3], where different types of phase equilibria play important roles. A typical example of such a process is fat splitting and its products separation. The fat splitting or lipids hydrolysis is known as Colgate Emery process [5], which is an old process, still applied worldwide today. The process consists of transforming the triglycerides into glycerol and fatty acids under temperature and pressure conditions, which ensure a conversion of triglycerides to over 95\% [6]. During this process two liquid phases are formed: an organic phase containing fatty acids with trace amounts of water, unreacted triglycerides, and intermediary products (mono- and di-glycerides), and an aqueous phase known as sweet water, which contains $12-18 \%$ glycerol. The resulting two liquid products, fatty acids and sweet water can be further separated. If the fatty acids mixture (organic phase) separation into high purity individual components is considered, several separation methods involving VLE or SLE can be used, e.g.: fractional distillation (VLE), steam stripping within vacuum condition (VLE)[7], or fractional crystallization (SLE) with or without using a solvent [8]. Glycerol 
concentration from the aqueous phase can be done through several evaporation steps coupled with distillation (VLE) as finishing step for high purity glycerol.

The processing pathway from fat splitting towards separation and purification of pure compounds, along with the involved phase equilibria, is shown in Figure 2. In order to be able to design and improve these processes, where several types of phase equilibria and properties are involved, a reliable set of thermodynamic models able to predict the correct phase behaviour of the involved compounds and mixtures are required.

[insert Figure 2 here]

Models, such as UNIQUAC and NRTL, have been used to predict LLE [9, 10] and VLE [11, 12], for lipid systems involved in biodiesel purification, but for problems involving many compounds belonging to different classes, extensive property and equilibrium data are needed. Using equations of state such as SAFT $[13,14]$ and CPA, $[15,16,17]$ for lipids systems with strong associative interactions, like alcohol-ester, glycerol-alcohol, give good results, but unfortunately their prediction is limited to few compounds combinations (e.g.:, fatty acids-fatty acids, fatty esters with fatty esters or alcohol) and cannot be extrapolated to other type of lipids mixtures involving more complex compounds ( e.g.: systems with TAG, DAG, MAG, etc.) As these models (UNIQUAC, NRTL as well as SAFT, CPA) need molecular interaction parameters that are usually regressed from binary molecular mixtures, they are not predictive and need specific phase equilibrium data for all involved compounds. Therefore, group contribution (GC) based methods that can predict the molecular interactions from the group interactions are an option worth investigating because of limited data availability and the need for extrapolation beyond the systems for which phase equilibrium data is available.

GC based methods can provide a wide range of properties for pure compounds and their mixtures, making them an indispensable tool for process design and related analyses when no data or only few data is available. The UNIFAC model is one of the most well-known and widely applied group contribution based methods for liquid phase activity coefficient calculations. The Original UNIFAC-VLE model published in 1975 [18] is the first model variant of this series of models. Over the past few decades, many researchers have proposed extensions of this model for improving its performance: addition of new groups, fine-tuning of available binary group interaction parameters or changes made to the activity coefficient model equation. Some examples include (1) adaptations of the model for specific systems e.g. aqueous and nonaqueous sugar solutions [18]-[19], solvent-polymer systems [21], solutions of alkyl methanoates and alkanes [22], refrigerants [23], ionic liquids [24], polyol-water systems [25] and others; and (2) new procedures for re-fitting the parameters , e.g.: NIST-KT UNIFAC [26] and NISTmodified UNIFAC [27]. Different UNIFAC-based models have also been proposed by using modified equations for the binary group interaction parameters: Linear UNIFAC [28], Modified UNIFAC (Lyngby) [29] or Dortmund UNIFAC [30], or by trying to supplement the missing binary group interaction parameters, UNIFAC-CI [31]. 
Literature UNIFAC-based models did not result to good predictions for lipid systems: high deviations of the predicted versus experimental temperature, and unreal phase split (see Figure 3b, 11 and 13). An example is presented for two systems containing monocaprylin, Figure 3, where the following UNIFAC models were used: Original UNIFAC [18], Modified UNIFAC (Lyngby) [29], Linear UNIFAC [28], NIST-KT UNIFAC [26], Dortmund UNIFAC [30] and NIST-modified UNIFAC [27]. For the monocaprylin-hexanoic acid (Figure 3a), the best prediction is given by the Linear UNIFAC and NIST-KT UNIFAC. For monocaprylin-methyl hexaonate (Figure $3 b$ ), all models fail to predict the system behaviour, while Original UNIFAC gives an unreal liquid-liquid phase split in $\mathrm{x}=0.4-0.8$ region. Please note that NIST-KT UNIFAC has the same formulation as the Linear UNIFAC model [28], also known as KT-UNIFAC first order [32], [31], but the binary interaction parameter matrix is extended and fine-tuned using critically evaluated data with the NIST ThermoData Engine (TDE) software [26]; while NISTmodified uses Dortmund-UNIFAC model with a new binary interaction parameter matrix. Since none of the used models are describing the lipids systems well enough, an improved model is needed.

[insert Figure 3 here] [33]

In this work, a systematic identification-regression method for regression of selected model parameters applied for phase equilibrium property modelling is presented. The method provides a detailed approach for data selection and a regression procedure for binary interaction parameter estimation for group contribution based models. The aim is to offer support for a faster assessment and solution of the identification-regression problem.

The method presented here has the following characteristics: inclusion of a detailed algorithm for data selection, which complements personal judgment and available expertise; use of an efficient calculation sequence, which can be further exploited for planning experimental data collection in order to fill in the gaps within the binary interaction matrix and to make possible the step by step estimation of the binary group interaction parameters; the regression problem formulation and solution for each regression step. The important aspect, to note here, is that the complete data-set is divided into sub-sets ordered in a hierarchical manner for regressing the binary group interaction parameters associated with only the sub-sets. A final optimization is made, if necessary, with the full set, for final fine-tuning of the parameters. In this way, the full set of parameters can be regressed efficiently and quickly.

The identification method is applied to estimate binary group interaction parameters for the Original UNIFAC model dedicated to lipids systems. The objective is that the new set of parameters must be able to improve the performance of the original UNIFAC model with published parameters quantitatively as well as qualitatively by eliminating the prediction inaccuracies and/or uncertainties. The identification method uses the SPEED Lipids database, 
described in Section 2, as a source for experimental data and models for estimation of pure compound properties of lipids.

\section{SPEED LIPIDS DATABASE}

Thermodynamic properties are needed in all stages of a process-product development: from design, optimization, and economic analysis to control system design, plant operation and product lifecycle, and they are often used via computer-aided methods and tools. The few amounts of experimental data in the open literature for both lipids pure compounds and their mixtures resulted in the need of a lipids specialized database to ensure easy and fast access to available methods and tools for process and product design. Developments within lipids property modelling have been reported for different properties: critical properties [34], vapour pressure [35], heat of vaporization [35], heat capacity [36], viscosity [37], heat of fusion [38], heat of formation [38]. Some of these models were used for the development and extension of SPEED Lipids database [38]. In this paper, new developments and extension of the database are presented.

The database is structured in two parts: a part for pure compound properties and a part for mixture properties, each of them having associated experimental data and property models. The database is connected to the lipids toolbox, which has different features, allowing for a better exploration-use of the database. The features of the lipids toolbox are:

- Database search for pure compound experimental data or property models

- Optimization based data regression, which allows estimation of models parameters for new pure compound data

- Pure compound property data consistency check performed for classes of compounds by checking the variation/trend of a property against the carbon atoms number

- Database management, which allows the database connection to process simulators such as PRO II [39] and ICAS[40], and a product simulator (the Virtual Product-Process Design Laboratory [41], [42]) via XML files. These files can be imported by the simulators as private user libraries allowing thereby a wider use of the database.

\subsection{Pure compounds properties and property models}

The pure compound property part of the database contains 334 compounds classified within 18 categories of lipids, as given in Table 1. Other categories contain non-lipids compounds such as: glycerol, alcohols, and solvents involved in different lipids processes. For some of these 
compounds experimentally measured pure component property data is available, which cover primary, secondary and functional properties [43], as listed in Table 2 together with associated property models. These data cover seven primary properties and six functional properties. As can be noted from Tables 1-2, the experimentally measured primary property data cover less than $10 \%$ of the compounds of interest, with most data being for normal melting and boiling points. Experimentally measured data for functional properties is available for approximatively $15 \%$ of the compounds. It is important to note that there is no compound for which is available a full set of experimentally measured property data.

[Insert Table 1 here]

[Insert Table 2 here]

The correlations used for the functional properties are standard DIPPR correlations [44]. These were chosen for easier application/usage of the database with process simulators, where these correlations are readily available. The correlations used for the properties in the database are given in Table 3.

[Insert Table 3 here]

\subsection{Mixture properties and property models}

SPEED Lipids Database contains around 600 data sets for all type of phase equilibria including binary as well as multicomponent data, as given in Table 4 [45]. A part of the LLE multicomponent systems have been collected from Bessa et al [46]. Among binary VLE data systems, $28.3 \%$ correspond to fatty acids and fatty esters, while $56.5 \%$ of the data sets correspond to systems containing glycerol with alcohols and water. Regarding the LLE multicomponent data, over $70 \%$ of the data sets are related to biodiesel processing, most of the mixtures containing fatty esters with methanol, water and edible oils represented through pseudo-compounds. Among SLE binary data systems 53.5\% correspond to fatty acids and fatty esters systems.

Property models for phase equilibrium calculations, as well as some mixture related properties are available in the database: NRTL, UNIQUAC, Original UNIFAC, UNIFAC-CI models for liquid phase activity coefficient predictions used for phase equilibrium calculations. PC-SAFT model is available for SLE calculations as well as pure compound vapour pressures, density, specific heat and heats of vaporization predictions. The SPPED Lipids Database also has property models for predictions of dynamic liquid viscosity, surface tension, hydrophiliclipophilic deviation, and hydrophilic-lipophilic balance for mixture properties [47]. 
[insert Table 4 here]

\section{SYSTEMATIC IDENTIFICATION METHOD FOR PHASE EQUILIBRIA MODELLING}

This identification method aim is to regress the model parameters systematic, thermodynamically consistent and numerically efficient. The method breaks down the data-set into sub-sets to which model parameters are associated to and establish an estimation order for each sub-set. The main objective of model parameters regression is to improve the quality and reliability of the selected model for prediction of phase equilibrium calculations.

Group contribution based models like the Original UNIFAC model, uses binary group interaction parameters $\left(a_{m n}\right)$ which are needed for each pair of groups $m$ and $n$, to calculate the liquid phase activity coefficients needed in phase equilibria computations [18]. The expression for obtaining the activity coefficients according to this model is given by Eq 1, which is the sum of combinatorial and residual terms. The combinatorial and residual terms are dependent on the mixture composition $\left(x_{i}\right)$, volume and surface area group parameters $\left(q_{m}, r_{m}\right)$ while the residual term is also a function of the binary group interaction parameters (see Eqs. 2-3)

$$
\begin{aligned}
& \ln \gamma_{i}=\ln \gamma_{i}^{C}+\ln \gamma_{i}^{R} \\
& \gamma_{i}^{C}=f\left(x_{i}, \mathrm{q}_{m}, \mathrm{r}_{m}\right) \\
& \gamma_{i}^{R}=f\left(x_{i}, \mathrm{q}_{m}, a_{m n}\right)
\end{aligned}
$$

A difficult problem in parameter estimation, in general and phase equilibria predictions in particular, is the selection and evaluation of the experimentally measured data to be used for the regression step. The proposed identification method aims to compliment available expertise and personal judgment regarding data selection by providing a clear data selection algorithm as illustrated in Figure 4.

[insert Figure 4 here]

Regression of binary group interaction parameters for different type of chemical systems can prove to be difficult due to the problem size [27]. One-step regression of all parameters is impractical due to the large space of the optimization problem involving a high number of parameters, data, and local (sub-optimal) solutions. Also, long convergence times are a problem. The identification method provides a clear step by step procedure for model parameter 
estimation based on available data, which is organized into sub-sets from which only certain parameters are regressed. For this reason, the binary lipid systems are classified into categories, each one containing a sub-set of data.

The identification method is tested in this paper for regression of the original UNIFAC model binary group interaction parameters and the VLE data-sets of lipid systems that are available in the SPEED Lipids Database. It is well-known that the original UNIFAC model does not provide good predictions with the same set of binary group interaction parameters for VLE, LLE and SLE [48]. Therefore, in this paper, the binary group interaction parameters are regressed only with VLE data and then tested for extrapolation features with the SLE data. Only binary VLE data is considered for parameter regression since multicomponent data cannot give a unique match of the VLE compositions. Also, the quality of the data are checked first through established consistency tests [49].

The identification method consists of three hierarchical parts: (I) data collection and analysis, (II) data organization and selection, and (III) parameter estimation and validation, as highlighted in Figure 3. In this section the steps involved with each part of the method and the associated algorithms are presented.

\subsection{Data collection and analysis}

The objective here is retrieve-collect all available data (step 1) for the defined problem and to analyse the data in terms of physical check of errors (step 2) and testing for data quality (step 3).

Step 1 - Data Collection: Binary VLE and SLE data for lipids systems are collected-retrieved from different databases containing VLE data (e.g. ThermoData Engine software (TDE) from NIST [50], DECHEMA database[51], SPEED Lipids Database [38]), or from laboratory measurements.

Step 2 -Data check: Collected VLE and SLE data sets are checked for outlier errors, transcript errors, and availability of pure compound data (e.g.: vapour pressure, melting point). If the pure component data points are missing, these are added to the data sets. The values are taken from literature or databases if available; otherwise they are estimated by using property models for pure compounds.

Step 3 - Data quality testing: For the checked data-sets from Step 2, thermodynamic consistency tests are performed. VLE data evaluation is performed with ThermoData Engine (TDE) software from NIST [52], which assigns a quality factor to each data set according to Eq.4.

$Q_{V L E}=F_{\text {pure }}\left(F_{\text {test1 } 1}+F_{\text {test } 2}+F_{\text {test } 3}+F_{\text {test } 4}+F_{\text {test5 } 5}\right) ; Q_{V L E} \leq 1$ 
Where $Q_{V L E}$ [49] is the quality factor and can vary between 0 and $1, F_{\text {pure }}$ is the factor associated to pure component test [49], $F_{\text {test1 }}$ to $F_{\text {test5 }}$ are the quality factors associated to van Ness[53], Herington [54], Point [55],[56], Infinite dilution[55],[56] and Equation of state [53,57] tests.

\subsection{Data organization and selection}

The objective is to assign the available VLE data to their corresponding category systems and then prepare sub-sets of data according to a pre-established order so that the model parameters can be regressed sequentially and efficiently (step 5); the data sets to be included in each sub-sets need to pass the quality test (step 6). First, however, the property model is selected and the compounds present in the data sets are represented by the model defined groups and the full set of binary group interaction parameters that are available/need to be estimated are listed.

Step 4 - GC model selection and molecular structure group definition and assignment: The main groups and subgroups of the selected GC model are listed and assigned to represent the compounds found in the VLE data sets. All the compounds found in the VLE data sets must be represented by the selected model groups. The set of binary group interaction parameters are then identified. An example of application of this step is given in Section 1 of the Supplementary material.

Step 5 - Data category-group assignment and quality sorting: The data organization algorithm (Algorithm A) is used to sort the data into different category-groups according to the involved binary group interaction parameters. The aim of the algorithm is to identify the category-groups and their order in such a manner that, in the estimation step, only a small set of additional binary group interaction parameters is estimated, keeping the previously estimated parameters unchanged. An example for data sorting is given in Supplementary material, Section 2.

Step 6 - Data selection: The objective of the data selection algorithm (Algorithm B) is to remove low quality data. The algorithm tries to consider binary systems coming from different references, if their quality factor is higher than 0.1 , in order to avoid systematic errors of the data. The algorithm is explained in section 3.1.5 and an example of its application is given in section 3 of the Supplementary material.

\subsection{Parameter estimation and validation}

The parameter regression problem is formulated as a least squares optimization problem and it is solved with the Harwell subroutineVA07AD [58]. The regressed binary group interaction parameters are tested on retrieved VLE data. Their extrapolation capabilities are as well tested using SLE data. 
Step 7 - Parameter sensitivity analysis: The parameter sensitivity analysis is performed for the category-groups where more than one binary interaction pair needs to be estimated. Original UNIFAC model published parameters are used as the reference point when available; otherwise a preliminary estimation of the parameters is performed in order to be able to do the sensitivity analysis.

Step 8 - Calculation sequence identification: From the category-groups available and from the sensitivity analysis, the calculation order of binary group interaction pairs is determined. The calculation sequence follows the category-groups and the sensitivity order. Most sensitive pairs within a category-group are estimated first.

Step 9 - Parameter estimation: The parameter estimation is performed according to the determined calculation sequence from the previous step. For given $Q_{m}$ (surface area) and $R_{m}$ (volume) of each group, the binary group interaction parameters $a_{m n}$ (see Eq. 3) are regressed to match the corresponding VLE data. The objective function to minimize is given by Eq. 6. Other objective functions may also be used, but they are not tried in this paper. It is beyond the scope of this paper to analyse the performance of the objective function or numerical solver used. Equation 6 was however selected after a number of tests.

Step 10 - Parameter validation: For parameter validation, all the retrieved VLE data sets are used. The predictive power of the binary group interaction parameters is tested with the retrieved SLE data. ICAS-MoT [59] and PRO II [39] are used to perform the validation tests. Multicomponent VLE or SLE data can be used as well for validation, but care should be taken, since the probability of errors regarding the composition is higher.

\subsection{Algorithm A: Data organization}

The algorithm aims to organize the data within category-groups, with general notation X.M.N, according to the number of involved binary group interaction parameters pairs, $\mathrm{a}_{\mathrm{mn}}$ and $\mathrm{a}_{\mathrm{nm}}$ (called further pairs) $(\mathrm{X})$, the number of binary group interaction parameters pairs that need to be estimated (M), and type of involved binary interaction parameters pairs (N). For example, the category-group 3.2.1 as given in Table 6 in the category-group column and which involves 3 structure groups $\left(\mathrm{CH}_{2}, \mathrm{CH}_{3} \mathrm{OH}, \mathrm{CCOO}\right)$ has the following meaning for the category-group numbers: 3 corresponds to $\mathrm{X}$ and stands for the number of available binary group interactions parameters pairs given by the data sets from this category-group $\left(\mathrm{CH}_{2}-\mathrm{CH}_{3} \mathrm{OH}, \mathrm{CH}_{2}-\mathrm{CCOO}\right.$, $\mathrm{CH}_{3} \mathrm{OH}-\mathrm{CCOO}$ ), 2 correspond to $\mathrm{M}$ which gives the number of binary interaction pairs that will be estimated from the data sets available in this category-group. In the list of category-groups one can notice that the $\mathrm{CH}_{2}-\mathrm{CCOO}$ binary group interaction parameters pair is already identified for regression in category-group 1.1.2 (which comes before 3.2.1). This means that when performing the regression; when one reaches category-group 3.2.1 the $\mathrm{CH}_{2}$-CCOO binary pair interaction will be already known, leaving for regression just $\mathrm{CH}_{2}-\mathrm{CH}_{3} \mathrm{OH}$ and $\mathrm{CH}_{3} \mathrm{OH}-\mathrm{CCOO}$. 
The last number in the category-group is 1 which corresponds to $\mathrm{N}$ and denotes the type of the pair (the role of the last number is to differentiate between category-groups having the same number of involved and estimated binary group interaction parameters pairs). Another set of data involving 3 pairs with 2 needed to be identified, will get another value for $\mathrm{N}$, as it is the case for category-groups 3.2.2, 3.2.3, 3.2.5, and 3.2.6. The flow diagram of this algorithm is shown in Figure 5.

[insert Figure 5 here]

Step A.1. X, M, and N are initialized to zero. All pairs are considered as unknown/ unidentified.

Step A.2.Category (X) iteration loop starts

Step A.3. All the systems with X pairs are identified and selected.

Step A.4. Sub-category (M) loop starts

Step A.5. All the systems with $\mathrm{M}$ unknown/unidentified pairs are identified, selected and organized according to their type $(\mathrm{N})$.

Step A.6. All the pairs identified in Step A.5 are considered as known/identified.

Step A.7. Check remaining systems in $\mathrm{X}$ category for unknown /unidentified pairs. Are in the $\mathrm{X}$ category systems with $\mathrm{M}$ or less than $\mathrm{M}$ unknown pairs? If Yes, go to Step A.5. If No, go to Step A.8.

Step A.8. Check remaining systems in X category for unknown /unidentified pairs. Are in the $\mathrm{X}$ category systems with more than M unknown pairs? If Yes, go to Step 4. If No, go to Step A.9.

Step A.9. Are there systems with more than $\mathrm{X}$ pairs? If Yes, go to Step A.2. If No, end the algorithm.

\subsection{Algorithm B: Data selection algorithm}

The aim of the algorithm is to select the best data to be used for regression. The algorithm tries to eliminate experimental uncertainty/systematic errors by requesting to select at least two different sources/references for estimating certain interaction parameter(s), but only if these data sets have a minimum required quality value. The algorithm is applied individually to each category-group identified in Step 5 of the identification method. The algorithm is composed of seven steps as presented in the following paragraphs. The flow-diagram for algorithm B is also shown in Figure 5 . 
Step B.1. Data set is checked for quality. If $\mathrm{Q}_{\mathrm{VLE}} \geq 0.5$, go to Step B.7. If $\mathrm{Q}_{\mathrm{VLE}}<0.5$, go to Step B.2.

Step B.2. If $\mathrm{Q}_{\mathrm{END}} \geq 0.5$, go to Step B.7., If $\mathrm{Q}_{\mathrm{END}}<0.5$, go to Step B.3.

Step B.3. If the selected VLE data sets come from more than two different references, go to Step B.4. If no, go to Step B.6.

Step B.4. The VLE data set is not selected. Go to Step B.5.

Step B.5. If there are more data sets to be checked, go to Step B.1. If no, go to END of the algorithm..

Step B.6. If the $\mathrm{Q}_{\mathrm{VLE}}>0.1$ go to Step B.7. If $\mathrm{Q}_{\mathrm{VLE}} \leq 0.1$, go to Step B.4.

Step B.7. Select the VLE data set for parameter estimation. Go to Step B.5.

END. End the algorithm for current category-group. Proceed to apply the algorithm to another category-group if available. Otherwise, go to Step 7 in the methodology.

\section{IDENTIFICATION METHOD APPLICATION AND DISCUSSION}

In this section the application of the identification method for estimation of Original UNIFAC model binary group interaction parameters dedicated to lipids systems is presented together with a discussion of the results obtained.

\subsection{Data collection and analysis}

All binary VLE data sets (176) from the SPEED Lipids Database [47], 174 sets are retrieved. If the data sets did not have the necessary pure compound property data, they are provided by using vapour pressure correlations for pure compounds from the SPEED Lipids Database. The consistency checks are performed with ThermoData Engine [60]. All the data sets show a generally low quality, as also confirmed by Cunico et al. [61] -only $10.55 \%$ of the data sets have a quality factor over 0.5 (where 1.0 is the highest and best), $38.51 \%$ of the data sets have the quality factor for end point test over $0.5,7.22 \%$ pass the Herrington test, $3.33 \%$ pass Van Ness test and only $1.67 \%$ passed the equation of state test. 


\subsection{Data organization and selection}

Initial attempts to represent the lipid compounds with the same published structural groups of the Original UNIFAC model resulted in poor predictions for systems containing acylglycerols. A

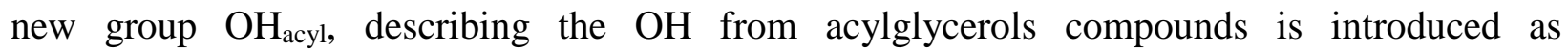
recommended by Cunico [45]. This group has also been used Bessa et al. [46] to describe the LLE behaviour for lipids. Original UNIFAC with published parameters is not able to correctly describe the VLE for glycerol-alcohol systems [62]. For this reason a new group defining the whole glycerol molecule, GLY, is introduced with the aim of improving the glycerol-alcohol predictions. The complete list of structural main-groups and sub-groups used to represent all the lipid compounds in the selected VLE data-sets and their surface area $\left(\mathrm{Q}_{\mathrm{m}}\right)$ and volume $\left(\mathrm{R}_{\mathrm{m}}\right)$ parameters, as determined by Bondi's method [63], are given in Table 5. For GLY, the R and Q parameters are calculated as sum of $\mathrm{CH}, \mathrm{CH}_{2}$ and $\mathrm{OH}$ contributions.

[insert Table 5 here]

The application of Algorithm A to analysed collected data from Step 1-3 results in identification of 25 binary group interaction parameters. The data is organized in 18 category-groups, as given in Table 6, indicating the need to estimate several pairs together. Once the data is sorted according to the quality factor in each of the category-groups, the Algorithm for data selection (Algorithm B) is applied. A total of 70 data sets are selected from the 174 identified (see Table $6)$.

\section{[insert Table 6]}

\subsection{Parameter estimation and validation}

In this section, the calculation sequence is presented along with the new set of binary group interaction parameters and their performances on VLE and SLE prediction. Based on calculation sequence, VLE data that need to be measured for extending the binary interaction parameter matrix, as well as, to improve parameters performances is identified.

\subsubsection{Calculation sequence}

For the category-groups where more than one binary group interaction parameters need to be regressed, the local differential sensitivity analysis is performed to identify which of the parameters are more sensitive. Different trials showed that if the most sensitive binary group interaction parameter pair is estimated first, better performances of the regressed parameters are achieved. The sensitivity analysis is performed in MoT [64] by varying the initial values of the parameters within $[-15 \%,+15 \%]$ interval with a $5 \%$ variation step. The order is retrieved based on the significance ranking values. The calculation sequence for category-groups identified with 
Algorithm A, and the sensitivity analysis is presented in Figure 6. The sensitivity within each category-group with more than one parameter decreases from left to right in the calculation scheme. The regression order of the binary group interaction parameters is from left to right and from top to down in the calculation sequence scheme. The relation between the parameters showed in the calculation sequence with arrows can be very useful when the user needs to reestimate a certain parameter, allowing a fast identification of all the other parameters that are dependent on this one.

[insert Figure 6 here]

For a better understanding of the calculation sequence two examples are presented:

- $\mathrm{COOH} / \mathrm{CCOO}$ binary interaction is estimated from the systems available in categorygroup 3.1.1. In this category-group, the following binary group interaction parameters are involved: $\mathrm{CH}_{2} / \mathrm{COOH}, \mathrm{CH}_{2} / \mathrm{CCOO}$ and $\mathrm{COOH} / \mathrm{CCOO}$. First the two binary pairs, $\mathrm{CH}_{2} / \mathrm{COOH}$ and $\mathrm{CH}_{2} / \mathrm{CCOOH}$, are estimated from category-groups 1.1.1 and 1.1.2, and their new values are used and kept constant for the estimation of the $\mathrm{COOH} / \mathrm{CCOO}$ pair.

- In group-category 3.2.1, the following binary group interaction parameters are involved: $\mathrm{CH}_{2} / \mathrm{CCOO}, \mathrm{CH}_{2} / \mathrm{CH}_{3} \mathrm{OH}$, and $\mathrm{CCOO} / \mathrm{CH}_{3} \mathrm{OH}$. In the first step, $\mathrm{CH}_{2} / \mathrm{CH}_{3} \mathrm{OH}$ pair is estimated by using and keeping fixed $\mathrm{CH}_{2} / \mathrm{CCOO}$, which is known from previous estimation, and $\mathrm{CCOO} / \mathrm{CH}_{3} \mathrm{OH}$, which uses the Original UNIFAC as initial value. In the second step, $\mathrm{CH}_{2} / \mathrm{CCOO}$ and $\mathrm{CH}_{2} / \mathrm{CH}_{3} \mathrm{OH}$ are kept constant and $\mathrm{CCOO} / \mathrm{CH}_{3} \mathrm{OH}$ is estimated. The values obtained for $\mathrm{CH}_{2} / \mathrm{CH}_{3} \mathrm{OH}$ in the first step are used now. Then a new regression is performed for the two binary pairs simultaneously, using the new values previously obtained for the two binary pairs. New values are stored and used further.

\subsubsection{Regression of model parameters}

The published parameters of Original UNIFAC model are used as initial estimates for the

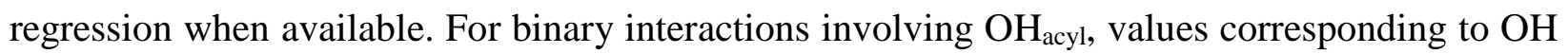
interactions are used as the initial estimate. For binary interactions involving GLY, zero is used as initial estimate. All the vapour pressure models of the involved compounds used for phase equilibria calculations are provided from the SPEED Lipids database.

Bubble P calculations using the gamma-phi approach are performed using Eq. 5. The activity coefficients in Eq. 5 are supplied by the original UNIFAC model, while, ideal gas model is assumed for the vapour phase.

$\Phi_{i} y_{i} P=\gamma_{i} x_{i} P_{i}^{\text {sat }}$

Eq. 5 
Where $\Phi_{i}$ is assumed to equal to 1 (ideal gas), $y_{i}$ - vapour phase composition, $P$ - total pressure, $\gamma_{i}$ - activity coefficient, $x_{i}$ - liquid phase composition, $P_{i}^{\text {sat }}$ - saturation pressure, $i$ - system compound (1 or 2$)$

The regression of the parameters is performed by minimizing the least squares (objective) function (see Eq. 7). This objective function, Eq 6, takes into account also the regularization term $[61,62]$ as given Eq.8.

$$
\begin{aligned}
& F_{o b j}=F_{P}+F_{R} \\
& F_{P}=\sum_{i}\left(\frac{P^{\text {experimental }}-P^{\text {calculated }}}{P^{\text {experimental }}}\right)_{i}^{2} \\
& F_{R}=\frac{1}{\beta} \sum_{m} \sum_{n}\left(a_{m n}-a_{m n}^{0}\right)^{2}
\end{aligned}
$$

Where $P^{\text {experimental }}$ and $P^{\text {calculated }}$ are experimental and calculated pressure, $\beta$ is an empirical term, set equal to $10^{5}, a_{m n}$ is estimated binary interaction parameter, and $a^{0}{ }_{m n}$ is the initial value of the binary interaction parameter, in this case Original UNIFAC published parameters value or zero for the GLY interactions.

The regressed values of the binary group interaction parameters are given in Table 7.

[insert Table 7 here]

\subsubsection{Regression analysis}

The regression analysis is performed using all available VLE data. The ARD(\%) for calculated VLE values using the regressed parameters and those calculated with the original UNIFAC model with published parameters [66] are given in Table 8. Only pressure deviation is reported for the $\mathrm{ARD}(\%)$ values since most of the data sets contain only information about liquid phase. For each category-group improvements in VLE prediction are made. The lipids based parameters lead to an overall improvement in $\mathrm{ARD}(\%)$ of $7.8 \%$ which corresponds to $35 \%$ improvement compared to the Original UNIFAC model with published parameters. The improvements are mostly due to the fact we are using new structural groups to describe the lipids (e.g.: $\mathrm{OH}_{\text {acyl }}$ for mono- and diacylglycerols, and GLY for glycerol molecule) and also new interaction parameter values.

[insert Table 8 here] 
The parity plot of the Original UNIFAC model with published and lipids based parameters prediction is showed in Figure 7. Significant improvements for the model with the lipids based parameters can be noticed. The prediction results are analysed also through the cumulative deviation plot, Figure 8. Differences between the model with the two sets of parameters, published and lipids based, start to appear when more than 600 data points are used. This behaviour is given by the ideal systems, e.g.: saturated fatty acids, saturated fatty esters systems, which present similar prediction performances with both sets of parameters, as showed in Figure 9 for hexanoic acid - octanoic acid system.

[insert Figure 7 here]

[insert Figure 8 here]

[insert Figure 9 here] [67]

\subsubsection{Model performances}

Original UNIFAC model description of different lipids systems using published parameters as presented in Figures 10 and 11 with dotted line, is not very accurate: deviations of the predicted versus experimental temperature (Figure 10), and unreal liquid-liquid phase split (Figure 11). Regression of the binary interaction parameters, Original UNIFAC model with lipids based parameters, improves the VLE prediction for the mentioned systems both quantitatively and qualitatively: lower deviations and the unreal liquid-liquid phase split is removed.

[insert Figure 10 here] [68]

[insert Figure 11 here] [69]

Figure 12 and 13 present the performances of Original UNIFAC model with published and lipids-based parameters for monocaprylin systems. Addition of the $\mathrm{OH}_{\text {acyl }}$ group and the new values of the interaction parameters help the VLE description of systems with monoacylglycerol e.g.: better fitting, no unreal phase split (Figure 13). The $\mathrm{OH}_{\text {acyl }}$ was introduced because of a different behaviour of $\mathrm{OH}$ group compared to the one present in small chain alcohols. The different behaviour of the $\mathrm{OH}$ group in monoacylglycerol molecules is given by the effects of a secondary $\mathrm{OH}$ group, as well as, the influence of the rest of the molecule (big molecule compared to small chain alcohols).

[insert Figure 12 here] [33]

[insert Figure 13 here] [33] 
A similar problem can be present for systems with glycerol, where the three $\mathrm{OH}$ groups are connected to adjacent carbon atoms and lead to strong intra- and intermolecular interactions $[27,46]$. For this reason a group to describe the whole glycerol molecule, GLY, was introduced. The same approach was used in the NIST-modified UNIFAC model [27], and in the latest extension of Dortmund UNIFAC [70,71]. The use of the GLY group improves the prediction in systems with glycerol: glycerol-alcohol, Figure 14-16, glycerol-water, Figure 17. Unfortunately considerable deviations are still available, especially for the glycerol-water systems (Categorygroup 1.1.4).

[insert Figure 14 here] [17]

[insert Figure 15 here] [72]

[insert Figure 16 here] [17]

[insert Figure 17 here] [72]

It should be highlighted that the model developed in this work, Original UNIFAC model with lipids-based parameters, should be used only for lipids systems. Also, mixing the lipids-based parameters with parameters from other models should be avoided. Further fine-tuning of parameters resulted from category-groups with few data sets (e.g.: 3.1.1, 3.2.1, 3.2.2, 3.2.3, 6.1.1, 6.1.3, 6.3.1, 6.1.4, 6.3.1, 6.3.2) should be considered when new data will be available.

\subsubsection{SLE parameter extrapolation performances}

The parameters obtained with the method are extrapolated to SLE prediction for lipids systems. The SLE data extracted from SPEED Lipids database is organized in category-groups by applying the data organization algorithm (Algorithm A). For consistency, the same name of category-groups from VLE is used for describing the SLE data sets. A new category-group is defined in the case of SLE, named "Others". This category-group contains unsaturated triacylglycerols - saturated fatty acids and saturated triacylglycerols - unsaturated fatty acids type of systems. The SLE data used for testing the extrapolation capabilities of the parameters is given in Table 9.

[insert here Table 9]

All the SLE calculations are performed with ICAS-MoT [59] . SLE is calculated using Eq. 9. The melting temperature $\left(T_{m}\right)$ is taken from literature when data is available; otherwise values from SPEED Lipids Database are used. The values used in the calculations for heat of fusion $\left(H_{f}\right)$ are taken from SPEED Lipids Database. 


$$
\ln \left(\gamma_{i} x_{i}\right)=\frac{\Delta H_{f}}{R}\left(\frac{1}{T_{m, i}}-\frac{1}{T}\right)
$$

where $\gamma_{i}$ is the activity coefficient of compound $i, x_{i}$ is the mole fraction of the compound with higher melting point, , $\Delta H_{f}$ is the fusion enthalpy of compound $i$, $\mathrm{R}$ is the ideal gas constant, $T_{m, i}$ is the melting point of compound $i$, and $T$ is the mixture melting temperature.

The extrapolation results for Original UNIFAC model using both published and lipids based parameters are listed in Table 10. A slight overall improvement in SLE prediction is noticed for Original UNIFAC model using lipids based parameters compared to the published parameters. The biggest improvement is noticed for 6.3.2 and "Other" category-groups. It has to be taken into account that the parameters are not only extrapolated to another type of phase equilibria, but also to another range of temperatures.

[insert here Table 10]

Two examples of SLE prediction of the Original UNIFAC model with the published and lipids based parameters are presented in Figure 18-19. The performances of Original UNIFAC model with both published and lipids based parameters predictions are presented in the parity plot of predicted vs. experimental temperature of all SLE data involved, Figure 20, where small improvements can be noticed.

[insert Figure 18 here] [73]

[insert Figure 19 here] [72]

[insert Figure 20 here]

\subsubsection{Need for new data}

Insufficient experimental data or low quality data represent the main drawback in developing and extending the predicting capabilities of any property model. For lipids systems with unsaturated compounds, which involve $\mathrm{CH}=\mathrm{CH}$ group, very little data is available which leads to gaps in the interaction matrix, and to parameters with high uncertainty. Even though in the selection algorithm the quality of the data is considered for selecting a data set or not, overall low quality data sets for the same interaction parameters will lead to uncertainties for these parameters. Also, the low quantity of the data, will not allow to perform the VLE validation for certain groups interactions (e.g. as the case for the category-groups 3.1.1, 3.2.1, 3.2.2, 3.2.3, 6.1.1, 6.1.3, 6.3.1, 6.1.4, 6.3.1, 6.3.2). Some of the parameters from the mention category-groups are though checked when they are extrapolated for SLE prediction. The methodology, and especially the resulted calculation sequence, can be used for identifying and planning necessary phase equilibria data in order to cover the gaps within the binary interaction matrix, improve the 
parameters prediction and to have a regression in a step by step approach for all the binary pairs involved. Examples of systems that would require VLE measurements are presented in Table 11, and they are classified into four categories: data sets for step-by-step regression, data sets to fill in the gaps within the interaction matrix, data sets to improve the performances of the available binary group interaction parameters, and other systems involved in lipids related processes. When some or all types of data mentioned in Table 11 become available, a re-estimation of (certain) parameters using the proposed method should be performed.

[insert here Table 11]

\section{CONCLUSIONS}

The SPEED Lipids database presents an extensive collection of experimentally measured data and property models, which are used for regressing property model parameters for lipids systems. The database is organized in two parts: pure compounds part and mixtures part, each of them having their experimentally measured data and associated property models. The lipids toolbox allows a better exploration of the database by, for example, efficient data search, optimization based data regression, and consistency check for pure compounds. The database management via XML files allows the database connection to computer aided tools such as a commercial process simulator (PRO II) and a product simulator (VPPD-Lab).

A systematic identification method for phase equilibrium calculations has been presented. The method contains two algorithms, a data selection algorithm and a data organization algorithm, and allows a detailed parameter regression for the selected data and property model. The calculation sequence generated by the identification method could be further used to identify the necessary data to fill in the gaps within the binary interaction matrix and to plan the experiments.

The method has been applied for regression of Original UNIFAC model binary group interaction parameters dedicated to lipids systems. The new set of parameters for lipids improves the performance of the original UNIFAC model quantitatively as well as qualitatively. The addition of the two new groups, $\mathrm{OH}_{\text {acyl }}$ and GLY, provides significant improvement in VLE predictions. $\mathrm{OH}_{\text {acyl }}$ interaction helps to eliminate the unreal phase split for monocaylglycerol systems. GLY group and the related binary group interaction parameters give lower deviations in VLE predictions for glycerol systems compared to the original published parameters, but significant deviation for these types of systems are still available. An overall better fit of experimentally measured data is given by the new matrix of binary group interaction parameters even though for certain parameters there is insufficient experimentally measured data. Further, the validation of the parameters is done by extrapolating them to SLE prediction, where small improvements in prediction are achieved for lipids based parameters compared to the published parameters. The 
main drawback in developing and extending the predicting capabilities of the model remains the amount and quality of the available data.

\section{REFERENCES}

[1] E. Fahy, S. Subramaniam, R.C. Murphy, M. Nishijima, C.R.H. Raetz, T. Shimizu, F. Spener, G. Van Meer, M.J.O. Wakelam, E.A. Dennis, Update of the LIPID MAPS comprehensive classification system for lipids 1, J. Lipid Res. 50 (2009) 9-14.

[2] W. De Greyt, Edible Oil Refining: Current and Future Technologies, in: W. Hamm, R.J. Hamilton, G. Calliauw (Eds.), Edible Oil Process., 2nd ed., John Wiley \& Sons, Oxford, 2013.

[3] IHS, Fats and Oils Industry Overview, [Online] www.ihs.com/products/fats-and-oilsindustry-chemical-economics-handbook (accessed April 5, 2017).

[4] OIL World Statistics, From Oil World September 2016, [Online] www.oilworld.biz.

[5] H.L. Barnebey, A.C. Brown, J. Am. Oil Chem. Soc. 25 (1948) 95-99.

[6] W.C. Wang, R.H. Natelson, L.F. Stikeleather, W.L. Roberts, Comput. Chem. Eng. 58 (2013) 144-155.

[7] R. Berger, W. McPherson, J. Am. Oil Chem. Soc. 56 (1979) 743A-744A.

[8] F. Shahidi, ed., Bailey's Industrial Oil and Fat, 6th ed., John Wiley \& Sons, Inc., New Jersey, USA, 2005.

[9] E.F. Andrade, L. Igarashi-Mafra, M.R. Mafra, M.L. Corazza, J. Chem. Thermodyn. 47 (2012) 213-218.

[10] R.C. Basso, C.A.S. da Silva, C. de O. Sousa, A.J. de A. Meirelles, E.A.C. Batista, Bioresour. Technol. 131 (2013) 468-475.

[11] R. Chen, H. Ding, M. Liu, H. Zhou, N. Chen, Fluid Phase Equilib. 382 (2014) 133-138.

[12] J. Hou, S. Xu, H. Ding, T. Sun, J. Chem. Eng. Data. 57 (2012) 2632-2639.

[13] M.L. Corazza, W.A. Fouad, W.G. Chapman, Fluid Phase Equilib. 416 (2016) 130-137.

[14] M.B. Oliveira, F. Llovell, M. Cruz, L.F. Vega, J.A.P. Coutinho, Fuel. 129 (2014) 116128. 
[15] M.B. Oliveira, L.A. Follegatti-Romero, M. Lanza, F.R.M. Batista, E.A.C. Batista, A.J.A. Meirelles, Fuel. 133 (2014) 224-231.

[16] I. Tsivintzelis, S. Ali, G.M. Kontogeorgis, Fluid Phase Equilib. 430 (2016) 75-92.

[17] M.B. Oliveira, A.R.R. Teles, A.J. Queimada, J.A.P. Coutinho, Fluid Phase Equilib. 280 (2009) 22-29.

[18] A. Fredenslund, R.L. Jones, J.M. Prausnitz, AIChE J. 21 (1975) 1086-1099.

[19] A.M. Peres, E.A. Macedo, Fluid Phase Equilib. 139 (1997) 47-74.

[20] S.A. Cooke, S.Ó. Jónsdóttir, P. Westh, Fluid Phase Equilib. 194197 (2002) 947-956.

[21] G. Wibawa, S. Takishima, Y. Sato, H. Masuoka, Fluid Phase Equilib. 202 (2002) 367383.

[22] J. Ortega, L. Fernández, G. Sabater, Fluid Phase Equilib. 402 (2015) 38-49.

[23] M. Kleiber, Fluid Phase Equilib. 107 (1995) 161-188.

[24] S.H. Kim, A. Anantpinijwatna, J.W. Kang, R. Gani, Fluid Phase Equilib. 412 (2016) 177198.

[25] C. Marcolli, T. Peter, Atmos. Chem. Phys. 5 (2005) 1545-1555.

[26] J.W. Kang, V. Diky, R.D. Chirico, J.W. Magee, C.D. Muzny, I. Abdulagatov, A.F. Kazakov, M. Frenkel, Fluid Phase Equilib. 309 (2011) 68-75.

[27] J.W. Kang, V. Diky, M. Frenkel, Fluid Phase Equilib. 388 (2015) 128-141.

[28] H.K. Hansen, B. Coto, B. Kuhlmann, IVC-SEP Internal Report SEP 9212, Institut for Kemiteknik, Technical University of Denmark, 1992.

[29] B.L. Larsen, P. Rasmussen, A. Fredenslund, Ind. Eng. Chem. Res. 26 (1987) 2274-2286.

[30] U. Weidlich, J. Gmehling, Ind. Eng. Chem. Res. 26 (1987) 1372-1381.

[31] A.A. Mustaffa, R. Gani, G.M. Kontogeorgis, Fluid Phase Equilib. 366 (2014) 24-44.

[32] J.W. Kang, J. Abildskov, R. Gani, J. Cobas, Ind. Eng. Chem. Res. 41 (2002) 3260-3273.

[33] L.P. Cunico, D.S. Damaceno, R.M. Matricarde Falleiro, B. Sarup, J. Abildskov, R. Ceriani, R. Gani, J. Chem. Thermodyn. 91 (2015) 108-115.

[34] J. Marrero, R. Gani, Fluid Phase Equilib. 183-184 (2001) 183-208. 
[35] R. Ceriani, R. Gani, Y.A. Liu, Fluid Phase Equilib. 337 (2013) 53-59.

[36] R. Ceriani, R. Gani, A.J.A. Meirelles, Fluid Phase Equilib. 283 (2009) 49-55.

[37] R. Ceriani, C.B. Gonçalves, J.A.P. Coutinho, Energy and Fuels. 25 (2011) 3712-3717.

[38] L.P. Cunico, A.S. Hukkerikar, R. Ceriani, B. Sarup, R. Gani, Fluid Phase Equilib. 357 (2013) 2-18.

[39] Schneider Electric Software, PRO/II ® 10.0 User Guide, Lake Forest, CA, USA, 2016.

[40] R. Gani, G. Hytoft, C. Jaksland, A.K. Jensen, Comput. Chem. Eng. 21 (1997) 1135-1146.

[41] S. Kalakul, S. Cignitti, L. Zhang, R. Gani, Integrated Computer-aided Framework for Sustainable Chemical Product Design and Evaluation, in: Z. Kravanja, M. Bogotaj (Eds.), Proc. 26th Eur. Symp. Comput. Aided Process Eng. - ESCAPE 26, Elsevier Masson SAS, 2016: 2343-2348.

[42] S. Kalakul, S. Cignitti, L. Zhang, R. Gani, VPPD-Lab: The Chemical Product Simulator, in: Comput. Aided Chem. Eng., Elsevier, 2017: 61-94.

[43] G.M. Kontogeorgis, R. Gani, Introduction to Computer Aided Property Estimation, in: G.M. Kontogeorgis, R. Gani (Eds.), Comput. Aided Prop. Estim. Preocess Prod. Des., 1st ed., ELSEVIER B.V., Amsterdam, 2004: 3-26.

[44] G.H. Thomson, The DIPPR ® Databases1, Int. J. Thermophys. 17 (1996) 223-232.

[45] L.P. Cunico, Modelling of Phase Equlibria and Related Properties of Mixtures Involving Lipids, PhD Thesis, Technical University of Denmark (DTU), 2015.

[46] L.C.B.A. Bessa, M.C. Ferreira, C.R.A. Abreu, E.A.C. Batista, A.J.A. Meirelles, Fluid Phase Equilib. 425 (2016) 98-107.

[47] S. Kalakul, Property Model-based Tailor-made Design of Chemical-based Products Property Model-based Tailor-made Design of Chemical-based Products, PhD Thesis, Technical University of Denmark (DTU), 2016.

[48] G.M. Kontogeorgis, G.K. Folas, Thermodynamic models for industrial applications : from classical and advanced mixing rules to association theories, Wiley, 2010.

[49] J.W. Kang, V. Diky, R.D. Chirico, J.W. Magee, C.D. Muzny, I. Abdulagatov, A.F. Kazakov, M. Frenkel, J. Chem. Eng. Data. 55 (2010) 3631-3640.

[50] V. Diky, R.D. Chirico, C.D. Muzny, A.F. Kazakov, K. Kroenlein, J.W. Magee, I. Abdulagatov, J.W. Kang, M. Frenkel, J. Chem. Inf. Model. 52 (2012) 260-76. 
[51] U. Westhaus, T. Droge, R. Sass, Fluid Phase Equilib. 158-160 (1999) 429-435.

[52] K. Kroenlein, C.D. Muzny, V. Diky, A.F. Kazakov, R.D. Chirico, J.W. Magee, I. Abdulagatov, M. Frenkel, J. Chem. Inf. Model. 51 (2011) 1506-1512.

[53] H.C. Van Ness, S.M. Byer, R.E. Gibbs, AIChE J. 19 (1973) 238-244.

[54] J. Wisniak, Ind. Eng. Chem. Res. 33 (1994) 177-180.

[55] K. Kojima, H.M. Moon, K. Ochi, Fluid Phase Equilib. 56 (1990) 269-284.

[56] K. Kurihara, Y. Egawa, K. Ochi, K. Kojima, Fluid Phase Equilib. 219 (2004) 75-85.

[57] E. Voutsas, V. Louli, C. Boukouvalas, K. Magoulas, D. Tassios, Fluid Phase Equilib. 241 (2006) 216-228.

[58] M.J. Hopper, Harwell Subroutine Library Catalogue, UK, 1973.

[59] M. Sales-Cruz, R. Gani, Comput. Chem. Eng. 16 (2003) 209-249.

[60] V. Diky, R.D. Chirico, A.F. Kazakov, C.D. Muzny, M. Frenkel, J. Chem. Inf. Model. 49 (2009) 503-517.

[61] L.P. Cunico, R. Ceriani, B. Sarup, J.P. O’Connell, R. Gani, Fluid Phase Equilib. 362 (2014) 318-327.

[62] J. Soujanya, C. Anvesh Reddy, B. Satyavathi, T. Sankarshana, , Fluid Phase Equilib. 409 (2016) 327-333.

[63] A. Bondi, Physical Properties of Molecular Crystans, Liquids and Glasses, Wiley, New York, 1968.

[64] M. Sales-Cruz, R. Gani, Model discrimination and parameter estimation through sensitivity analysis, in: W. Marquardt, C. Pantelides (Eds.), 16th Eur. Symp. Comput. Aided Process Eng. 9th Int. Symp. Process Syst. Eng., 2006.

[65] K. Balslev, J. Abildskov, Ind. Eng. Chem. Res. 41 (2002) 2047-2057.

[66] H.K. Hansen, P. Rasmussen, A. Fredenslund, M. Schiller, J. Gmehling, Ind. Eng. Chem. Res. 30 (1991) 2352-2355.

[67] A. Rose, J.A. Acciarri, E.T. Williams, Chem. Eng. Data Ser. 3 (1958) 210-212.

[68] J.A. Monik, H.D. Allen, C.J. Marlies, Oil Soap. 23 (1946) 177.

[69] M.B. Oliveira, Modelação do Equilíbrio de Fases na Produção de Biocombustíveis, $\mathrm{PhD}$ 
Thesis, Universidade de Aveiro, 2010.

[70] D. Constantinescu, J. Gmehling, J. Chem. Eng. Data. 61 (2016) 2738-2748.

[71] J. Gmehling, Fluid Phase Equilib. 398 (2015) 98-100.

[72] M.C. Costa, L.A.D. Boros, M.P. Rolemberg, M.A. Krähenbü, A.J.A. Meirelles, J. Chem. Eng. Data. 55 (2010) 974-977.

[73] K. Nishimura, K. Maeda, H. Kuramochi, K. Nakagawa, Y. Asakuma, K. Fukui, M. Osako, S. Sakai, J. Chem. Eng. Data. 56 (2011) 1613-1616. 


\section{Supplementary Material}

\section{Systematic Identification Method for Data Analysis and Phase Equilibria Modelling for Lipids Systems}

Olivia A. Perederic ${ }^{a}$, Larissa P. Cunico ${ }^{a}$, Sawitree Kalakul, ${ }^{a}$ Bent Sarup, ${ }^{b}$ John M. Woodley, ${ }^{a}$ Georgios M. Kontogeorgis, ${ }^{* b}$ Rafiqul Gani, ${ }^{a, c}$

${ }^{\text {a }}$ Department of Chemical and Biochemical Engineering, Technical University of Denmark,DK2800 Kgs. Lyngby, Denmark,

b Vegetable Oil Technology Business Unit, Alfa Laval Copenhagen A/S, DK-2860 Søborg, Denmark

${ }^{\mathrm{c}}$ PSE for SPEED, Skyttemosen 6, DK-3450 Allerod, Denmark

\section{Group definition and assignment (Method Step 4) example}

An example for Step 4, when the structural groups are defined and assigned to each compound and dataset is presented. The example is built for methyl laurate - lauric acid system:

- Methyl laurate: subgroup structure: $\mathrm{CH}_{3}$ x 2, $\mathrm{CH}_{2}$ x 9, $\mathrm{CH}_{2} \mathrm{COO}$ x 1; involved main groups: $\mathrm{CH}_{2}, \mathrm{CH}_{2} \mathrm{COO}$

- Lauric acid: subgroup structure: $\mathrm{CH}_{3} \times 1, \mathrm{CH}_{2} \times 10, \mathrm{COOH} \times 1$; involved main groups: $\mathrm{CH}_{2}, \mathrm{COOH}$

- System group interactions: $\mathrm{CH}_{2}-\mathrm{CH}_{2} \mathrm{COO}, \mathrm{CH}_{2}-\mathrm{COOH}, \mathrm{CH}_{2} \mathrm{COO}-\mathrm{COOH}$

2. Algorithm A application example 
For a better understanding of how the algorithm works, an example is presented. It is supposed that the whole database to be used for parameter estimation is composed of the VLE data sets given in Table 6.

For each of the 5 datasets, the structure group and available binary group interaction parameters are known from Step 4 of the method. The Algorithm A application will give following results:

Step A.1 The category group descriptors $\mathrm{X}, \mathrm{M}$ and $\mathrm{N}$ are initialised with zero.

Iteration I.a

Step A.2 X get the value $\mathrm{X}=1$

Step A.3 The systems with one interaction are: 1, 3, 4 and 6.

Iteration I.b

Step A.4 M get the value $\mathrm{M}=1$

Step A.5 The systems that will be in category group X.M $=1.1$ are $1,3,4$ and 6 . The type (N) of interactions available in the identified systems are: $\mathrm{CH} 2-\mathrm{COOH}(\mathrm{N}=1)$ for systems 1 and $6, \mathrm{CH}_{2}-$ $\mathrm{CH}_{2} \mathrm{COO}(\mathrm{N}=2)$ for system 4, and GLY-MeOH $(\mathrm{N}=3)$ for system 3. Note that the order of the system type is random and it does not affect in any way the calculation sequence.

Step A.6 All the binary pairs for the category groups X.M.N: 1.1.1, 1.1.2, and 1.1.3 are considered as known. This will help at identifying new interaction further when the algorithm is applied.

Step A.7 When $\mathrm{X}=1$, the only possible value for $\mathrm{M}$ is 1 , so no more systems are available. The option No is selected.

Step A.8. Similar as for the Step A.7, no more systems are available. The option No is selected.

Step A.9. There are systems with more than one binary interaction pair. The option Yes is selected.

Iteration II.a

Step A. $2 \mathrm{X}$ get the value $\mathrm{X}=1+1=2$

Step A.3 There are no systems with two binary interaction parameters, therefore nothing will happen in Steps A.4 to A.6.

Step A.7. No more systems to be identified. The option Yes is selected.

Iteration III.a

Step A. $2 \mathrm{X}$ get the value $\mathrm{X}=2+1=3$ 
Step A.3 Two systems presents 3 binary interaction parameters: system 2 and 5 .

Iteration III.b (1)

Step A.4 M get the value $\mathrm{M}=1$

Step A.5 The systems with one unknown binary interaction parameter are identified. The only system available with one unknown binary interaction pair is System 2. For this system, 2 out 3 binary interactions were identified in the previous iteration $\left(\mathrm{CH}_{2}-\mathrm{CH}_{2} \mathrm{COO}\right.$ and $\left.\mathrm{CH}_{2}-\mathrm{COOH}\right)$, meaning that the only unknown binary interaction parameter is $\mathrm{CH}_{2} \mathrm{COO}-\mathrm{COOH}$. System 2 will be part of 3.1.1 category group.

Step A.6 All the binary interaction parameters (from previous and current iteration) are consider as identified.

Step A.7 No more systems with one unknown parameters are available. The option No is selected.

Step A.8 In the $\mathrm{X}=3$ category there is still one more system remaining. The option Yes is selected.

Iteration III.b (2)

Step A.4 M gets the value $\mathrm{M}=1+1=2$

Step A.5 The systems with two unknown binary interaction parameters are identified: system 5. For system 5 only $\mathrm{CH}_{2}-\mathrm{CH}_{2} \mathrm{COO}$ interaction is known from before $\left(\mathrm{CH}_{2}-\mathrm{OH}_{\text {acyl }}, \mathrm{CH}_{2} \mathrm{COO}-\mathrm{OHacyl}\right.$ are unknown). This system will be part of the category group 3.2.1.

No more systems are available. Five category groups are identified $(1.1 .1,1.1 .2,1.1 .3,3.1 .1$, 3.2.1). The algorithm ends, and the user returns to the method Step 6, after the data in each category group is sorted according to the quality factor.

Table 1. Example of VLE datasets organized within category groups with Algorithm A.

\begin{tabular}{|c|c|c|c|c|c|}
\hline No & \multicolumn{2}{|c|}{ VLE dataset components } & \multirow{2}{*}{$\begin{array}{l}\begin{array}{c}\text { Identified } \\
\text { structure } \\
\text { groups }\end{array} \\
\mathrm{CH}_{2}, \\
\mathrm{COOH}\end{array}$} & \multirow{2}{*}{$\begin{array}{c}\begin{array}{c}\text { Identified binary } \\
\text { interaction } \\
\text { parameters }\end{array} \\
\mathrm{CH}_{2}-\mathrm{COOH}\end{array}$} & \multirow{2}{*}{$\begin{array}{c}\text { Category } \\
\text { Group } \\
\text { (X.M.N) } \\
1.1 .1\end{array}$} \\
\hline 1 & $\begin{array}{l}\text { Saturated fatty acid } \\
\text { (e.g.: Myristic acid) }\end{array}$ & $\begin{array}{c}\text { Saturated fatty acid } \\
\text { (e.g.: Stearic acid) }\end{array}$ & & & \\
\hline 2 & $\begin{array}{l}\text { Saturated fatty ester } \\
\text { (e.g: Methyl laurate) }\end{array}$ & $\begin{array}{l}\text { Saturated fatty acid } \\
\text { (e.g.: Myristic acid) }\end{array}$ & $\begin{array}{l}\mathrm{CH}_{2}, \\
\mathrm{CH}_{2} \mathrm{COO}, \\
\mathrm{COOH}\end{array}$ & $\begin{array}{l}\mathrm{CH}_{2}-\mathrm{CH}_{2} \mathrm{COO}, \\
\mathrm{CH}_{2}-\mathrm{COOH}, \\
\mathrm{CH}_{2} \mathrm{COO}-\mathrm{COOH}\end{array}$ & 3.1 .1 \\
\hline 3 & Glycerol & Methanol & $\begin{array}{l}\text { GLY, } \\
\mathrm{MeOH}\end{array}$ & GLY-MeOH & 1.1 .3 \\
\hline 4 & $\begin{array}{l}\text { Saturated fatty ester } \\
\text { (e.g: Methyl } \\
\text { stearate) }\end{array}$ & $\begin{array}{l}\text { Saturated fatty ester } \\
\text { (e.g.: methyl } \\
\text { laurate) }\end{array}$ & $\begin{array}{l}\mathrm{CH}_{2}, \\
\mathrm{CH}_{2} \mathrm{COO}\end{array}$ & $\mathrm{CH}_{2}-\mathrm{CH}_{2} \mathrm{COO}$ & 1.1 .2 \\
\hline
\end{tabular}




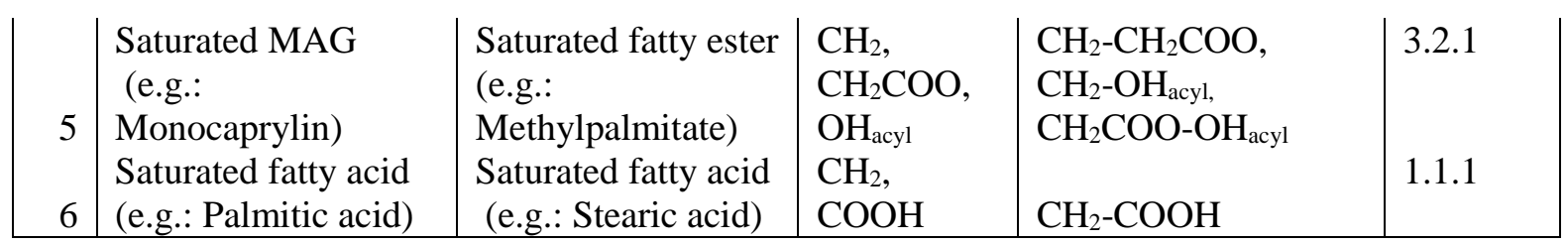

3. Algorithm B application example

An example for algorithm B for data selection is presented. Three category groups are used to show how algorithm B works. The algorithm is applied independently to each category group.

Category group 1.1.1

Iteration I

Step B.1 $Q_{V L E}$ for dataset 1 is higher than 0.5. The option Yes is selected.

Step B.7. The VLE data set is selected.

Step B.5 There are more data sets in this category group. The option Yes is selected.

Iteration II

Same steps/path is follows for the second iteration when VLE dataset 2 is selected.

Iteration III

Step B.1 $Q_{V L E}$ for dataset 1 is lower than 0.5. The option No is selected.

Step B.2 $Q_{\text {pure }}$ for dataset is higher than 0.5. The option Yes is selected.

Step B.7. The VLE data set is selected.

Step B.5 There are more data sets in this category group. The option Yes is selected.

Iteration IV

Step B.1 $Q_{V L E}$ for dataset 1 is lower than 0.5. The option No is selected.

Step B.2 $Q_{\text {pure }}$ for is lower than 0.5. The option No is selected.

Step B.3 The selected datasets belong to only one reference. The option No is selected.

Step B.6 $Q_{V L E}$ is higher than 0.1. The option Yes is selected.

Step B.7. The VLE data set is selected.

Step B.5 There are more data sets in this category group. The option Yes is selected. 
Iteration $\mathrm{V}$

Step B.1 $Q_{V L E}$ for dataset 1 is lower than 0.5. The option No is selected.

Step B.2 $Q_{\text {pure }}$ for dataset is lower than 0.5. The option No is selected.

Step B.3 The selected datasets belong to two references. The option Yes is selected.

Step B.4 The dataset is not selected.

Step B.5 There are no more data sets in this category group. The algorithm ends.

Category group 3.1.1

Step B.1 $Q_{V L E}$ for dataset 1 is lower than 0.5. The option No is selected.

Step B.2 $Q_{\text {pure }}$ for is lower than 0.5. The option No is selected.

Step B.3 There is no datasets previously selected (zero references). The option No is selected.

Step B.6 $Q_{V L E}$ is higher than 0.1. The option Yes is selected.

Step B.7. The VLE data set is selected.

Step B.5 There are no more data sets in this category group. The algorithm ends.

Category group 6.1.3

Iteration I

Step B.1 QvLE for dataset 1 is lower than 0.5. The option No is selected.

Step B.2 Q $\mathrm{Qure}_{\text {for }}$ is higher than 0.5. The option Yes is selected.

Step B.7. The VLE data set is selected.

Step B.5 There are more data sets in this category group. The option Yes is selected.

Iteration II

Step B.1 $Q_{V L E}$ for dataset 1 is lower than 0.5. The option No is selected.

Step B.2 $Q_{\text {pure }}$ for is lower than 0.5. The option No is selected.

Step B.3 There is no datasets previously selected (zero references). The option No is selected.

Step B.6 $Q_{V L E}$ is lower than 0.1. The option No is selected. 
Step B.4 The dataset is not selected.

Step B.5 There are no more data sets in this category group. The algorithm ends.

Table 2. Algorithm B application results to VLE datasets belonging to different category groups

\begin{tabular}{|c|r|l|l|r|r|r|l|}
\hline $\begin{array}{l}\text { Category } \\
\text { group }\end{array}$ & No. & \multicolumn{2}{|c|}{ VLE dataset components } & Ref. & $Q_{V L E}$ & $F_{\text {pure }}$ & $\begin{array}{c}\text { Algorithm B } \\
\text { result }\end{array}$ \\
\hline \multirow{4}{*}{1.1 .1} & 1 & Caprylic acid & Caproic acid & {$[1]$} & 0.65 & 0.93 & Selected \\
\cline { 2 - 8 } & 2 & Caprylic acid & Caproic acid & {$[1]$} & 0.56 & 0.93 & Selected \\
\cline { 2 - 8 } & 3 & Caprylic acid & Caproic acid & {$[1]$} & 0.49 & 0.76 & Selected \\
\cline { 2 - 8 } & 4 & Lauric acid & Myristic acid & {$[2]$} & 0.24 & 0.42 & Selected \\
\cline { 2 - 8 } & 5 & Caprylic acid & Capric acid & {$[3]$} & 0.10 & 0.10 & Not Selected \\
\hline 3.1 .1 & 1 & Methyl laurate & Lauric acid & {$[4]$} & 0.03 & 0.11 & Selected \\
\hline \multirow{2}{*}{6.1 .3} & 1 & Methyl oleate & EtOH & {$[5]$} & 0.25 & 0.50 & Selected \\
\cline { 2 - 8 } & 2 & Triolein & 2-propanol & {$[6]$} & $0.01<$ & 0.01 & Not Selected \\
\hline
\end{tabular}

\section{References}

[1] A. Rose and W. R. Supina, J. Chem. Eng. Data, 6 (1961), 173-179.

[2] E. Müller and H. Stage, Experimentelle Vermessung von Dampf-FlüssigkeitsPhasengleichgewichten. Berlin: Springer Verlag, 1961.

[3] L. Y. Akisawa Silva, R. M. Matricarde Falleiro, A. J. A. Meirelles, and M. A. Krähenbühl, Thermochim. Acta, 512 (2011), 178-182.

[4] J. A. Monick, H. D. Allen, and M. C. J, Oil Soap, 23 (1946), 177-182.

[5] M. B. Oliveira, S. I. Miguel, A. J. Queimada, and J. A. P. Coutinho, Ind. Eng. Chem. Res., 49 (2010), 3452-3458.

[6] G. H. Eduljee and A. P. Boyes, J Food Process Eng, 26 (1981), 55-57. 


\section{LIST OF FIGURES}

Figure 1. The evolution of lipids consumption between 1989 and 2017 [4]

Figure 2. Involved phase equilibria for fat splitting process and products separation (FA - fatty acids, $\mathrm{G}$ - glycerol, $\mathrm{W}$ - water).

Figure 3. VLE prediction using different UNIFAC models for monocaprylin (1) - hexanoic acid (2) system (a) and monocaprylin (1) - methyl hexanoate (2) system (b) at $2.50 \mathrm{kPa}$ [33]: experimental data, - Original UNIFAC, - Modified UNIFAC, - - Linear UNIFAC, - - NIST-KT UNIFAC, - - Dortmund UNIFAC, - - NIST-modified UNIFAC.

Figure 4. Flow-diagram for Systematic Phase Equilibria Modelling Method. Note: the required tools for each step are indicated by bold text in the input information column on the left hand side; the output information and/or results from each step are highlighted in the column on the right hand side.

Figure 5. Algorithms used with the method for data organisation (Algorithm A) and data selection (Algorithm B).

Figure 6. Parameter calculation sequence according to group-categories from Algorithm A and sensitivity analysis. The boxes contain information on parameter to be estimated and the categorygroup data sets that will be used for regression; dotted boxes are for the parameters that are estimated from the same category-group data sets. The regression of the parameters is performed from top to bottom and from left to right.

Figure 7. Parity plot of Original UNIFAC prediction using published and lipids based parameters vs. experimental pressure: $\diamond$ Original UNIFAC with published parameters, $\bigcirc$ Original UNIFAC with lipids based parameters.

Figure 8. Cumulative ARD\% for VLE prediction using Original UNIFAC model with published and lipids parameters: - - Original UNIFAC with published parameters, - Original UNIFAC with lipids based parameters.

Figure 9. VLE prediction using Original UNIFAC model with published and lipids based parameters for hexanoic acid (1) - octanoic acid (2) systems at $13.33 \mathrm{kPa}$ [67]: $\circ$ experimental data, - - Original UNIFAC with published parameters, - Original UNIFAC with lipids based parameters, red - vapour, blue - liquid.

Figure 10. VLE prediction using Original UNIFAC model with published and lipids based parameters for methyl laurate (1) - lauric acid (2) at $0.50 \mathrm{kPa}$ [68]: ० experimental data, - - Original 
UNIFAC with published parameters, — Original UNIFAC with lipids based parameters, red vapour, blue - liquid.

Figure 11. VLE prediction using Original UNIFAC model with published and lipids based parameters for methyl oleate (1) - methanol (2) system at $101.33 \mathrm{kPa}$ [69]: ० experimental data, - Original UNIFAC with published parameters, - Original UNIFAC with lipids based parameters, red - vapour, blue - liquid, light blue two phase split.

Figure 12. VLE prediction using Original UNIFAC model with published and lipids based parameters for monocaprylin (1) - palmitic acid (2) system at $2.50 \mathrm{kPa}$ [33]: ○ experimental data, - Original UNIFAC with published parameters, - Original UNIFAC with lipids based parameters, red - vapour, blue - liquid.

Figure 13. VLE prediction using Original UNIFAC model with published and lipids based parameters for monocaprylin (1) - methyl stearate (2) system at $1.20 \mathrm{kPa}$ [33]: $\circ$ experimental data, - - Original UNIFAC with published parameters, - Original UNIFAC with lipids based parameters, red - vapour, blue - liquid, light blue two phase split.

Figure 14. VLE prediction using Original UNIFAC model with published and lipids based parameters for glycerol (1) - methanol (2) system at $101.33 \mathrm{kPa}$ [17]: ० experimental data, - Original UNIFAC with published parameters, - Original UNIFAC with lipids based parameters, red - vapour, blue - liquid.

Figure 15. VLE prediction using Original UNIFAC model with published and lipids based parameters for glycerol (1) - ethanol (2) system at $66.70 \mathrm{kPa}$ [72]: ○ experimental data, - - Original UNIFAC with published parameters, - Original UNIFAC with lipids based parameters, red vapour, blue - liquid.

Figure 16. VLE prediction using Original UNIFAC model with published and lipids based parameters for glycerol (1) - 1-propanol (2) system at $101.33 \mathrm{kPa}$ [17]: ० experimental data, - Original UNIFAC with published parameters, - Original UNIFAC with lipids based parameters, red - vapour, blue - liquid.

Figure 17. VLE prediction using Original UNIFAC model with published and lipids based parameters for glycerol (1) - water (2) system $66.70 \mathrm{kPa}$ [72]: ० experimental data- - Original UNIFAC with published parameters, - Original UNIFAC with lipids based parameters, red vapour, blue - liquid.

Figure 18. SLE prediction using Original UNIFAC model with published and lipids-based parameters for stearic acid - trilinoleine [73]: $\circ$ experimental data- - Original UNIFAC with published parameters, - Original UNIFAC with lipids based parameters. 
Figure 19. SLE prediction using Original UNIFAC model with published and lipids-based parameters for tripalmitin -linoleic acid [72]: $\bigcirc$ experimental data- - Original UNIFAC with published parameters, - Original UNIFAC with lipids based parameters.

Figure 20. Parity plot for SLE predicted temperature using Original UNIFAC model with published and lipids based parameters vs. experimental temperature: $\diamond$ Original UNIFAC with published parameters, $\bigcirc$ Original UNIFAC with lipids based parameters. 


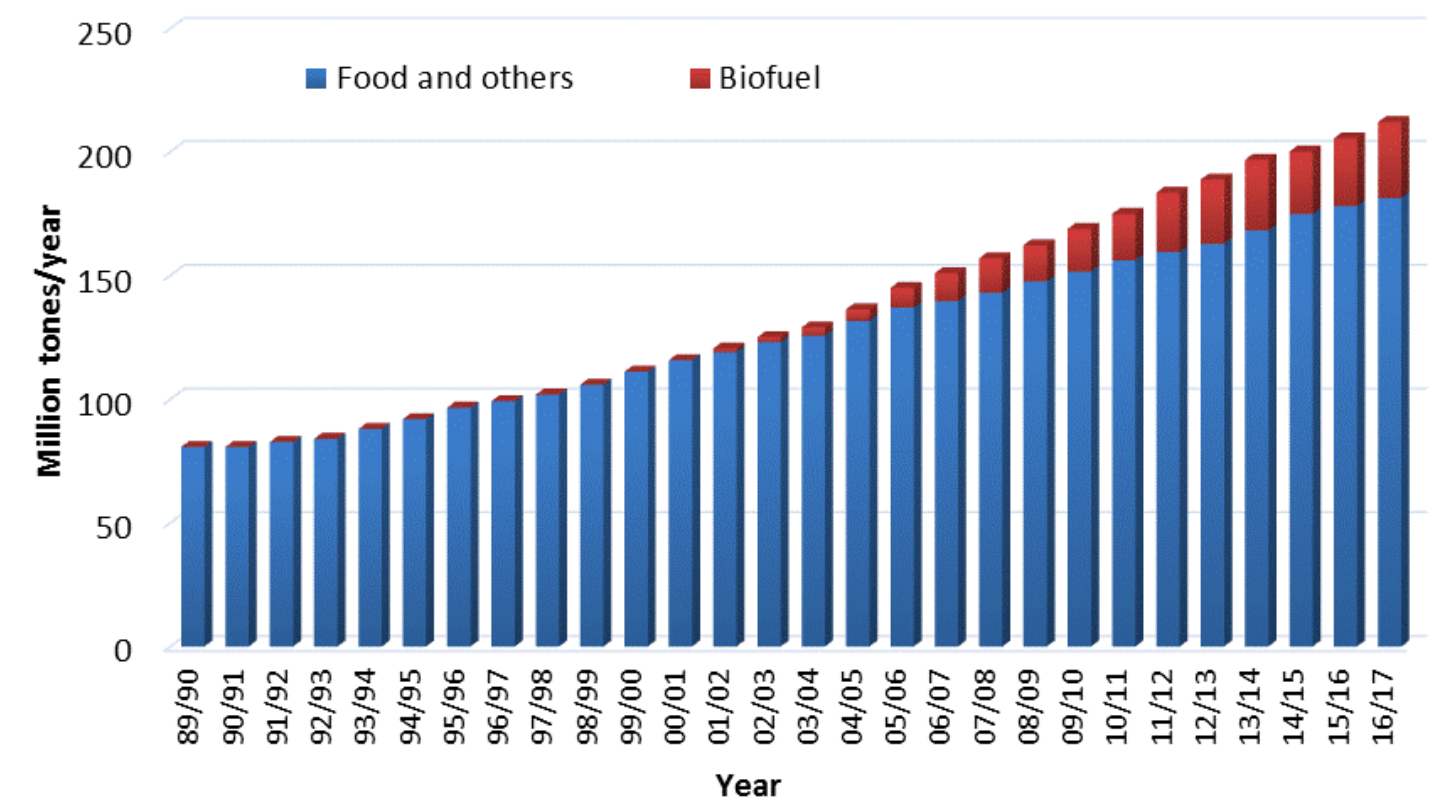

Figure 1. The evolution of lipids consumption between 1989 and 2017 [4]. 


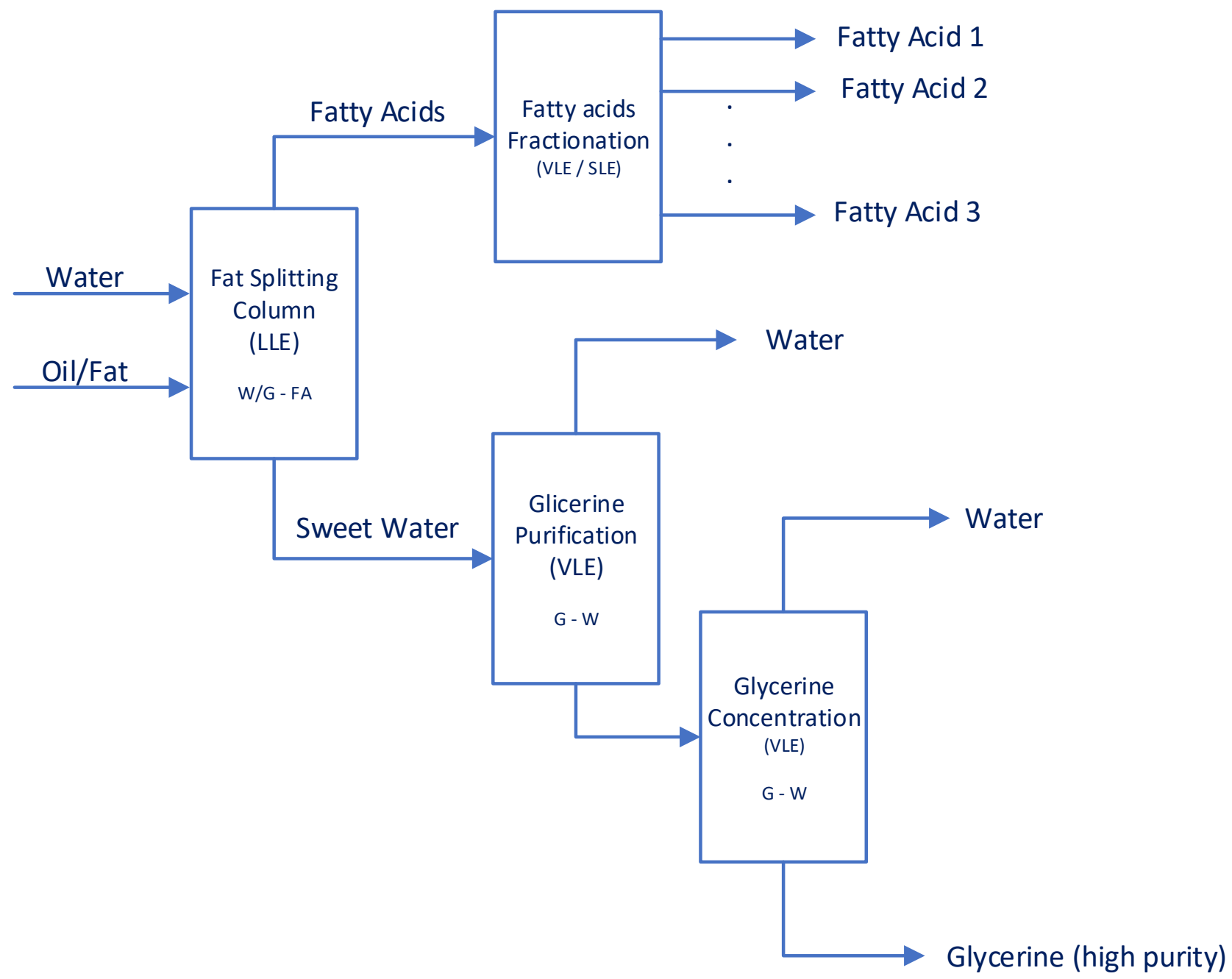

Figure 2. Involved phase equilibria for fat splitting process and products separation (FA - fatty acids, $\mathrm{G}$ - glycerol, W - water). 


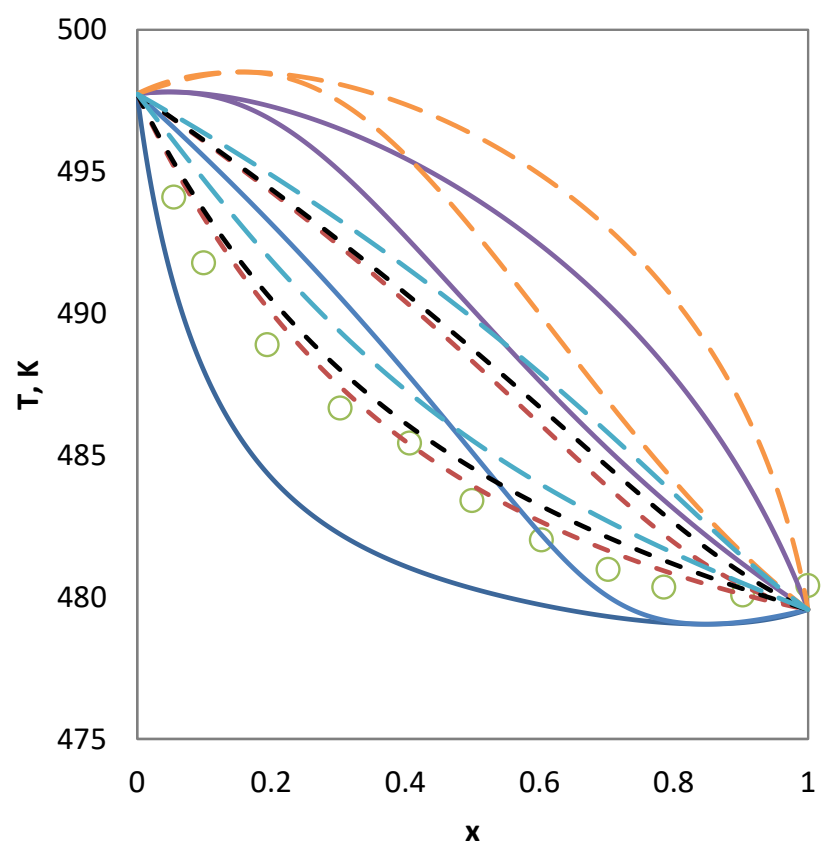

(a)

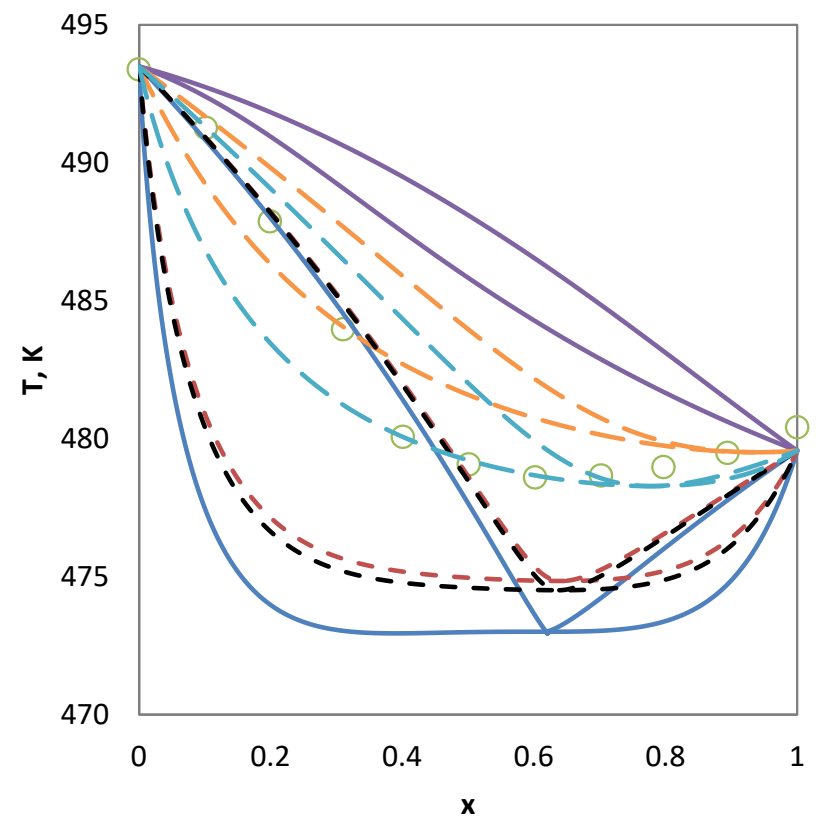

(b)

Figure 3. VLE prediction using different UNIFAC models for monocaprylin (1) - hexanoic acid (2) system (a) and monocaprylin (1) - methyl hexanoate (2) system (b) at $2.50 \mathrm{kPa}$ [33]: experimental data, - Original UNIFAC, - Modified UNIFAC, - - Linear UNIFAC, - - NIST-KT UNIFAC, - - Dortmund UNIFAC, - - NIST-modified UNIFAC. 


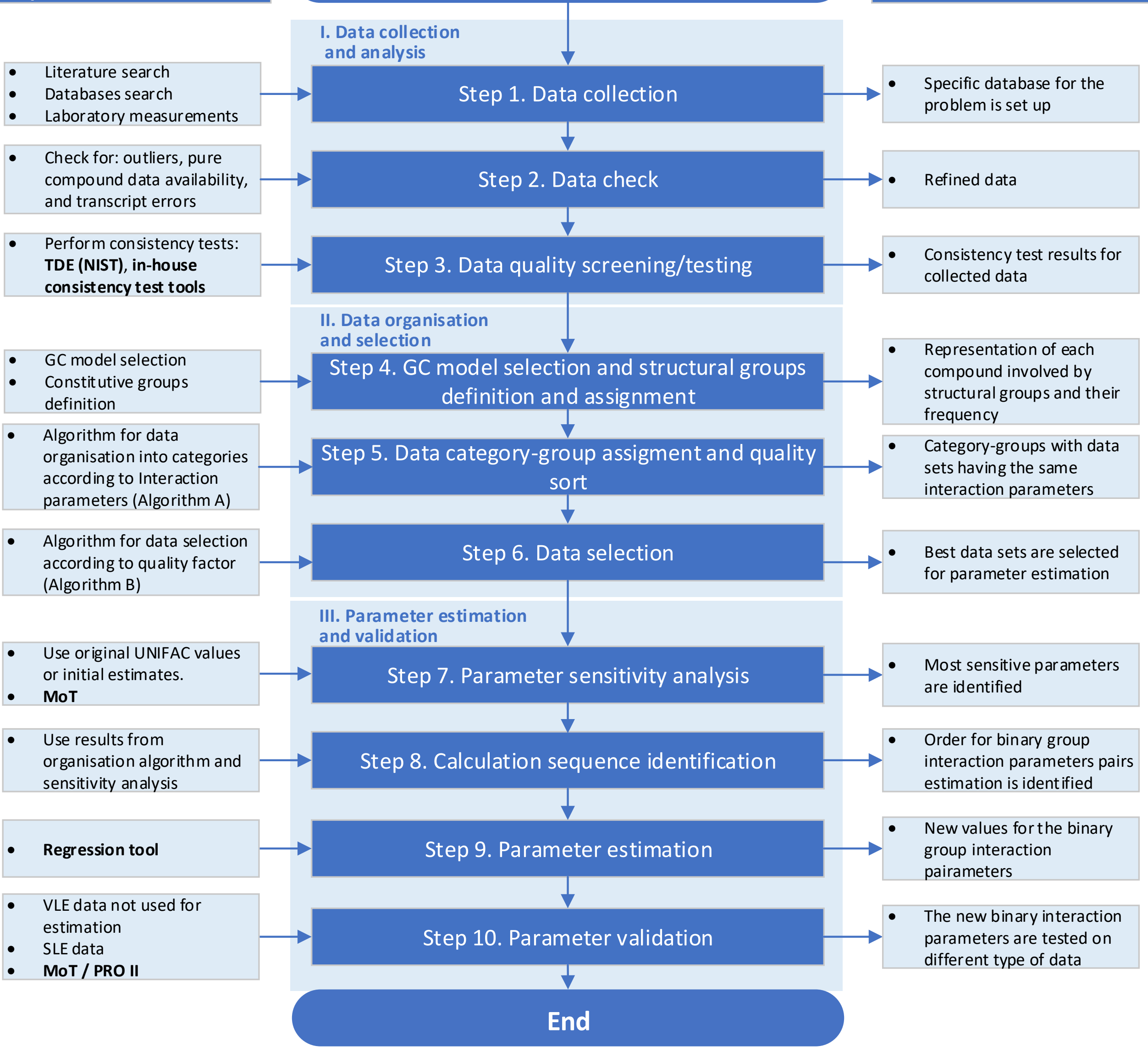

Figure 4. Flow-diagram for Systematic Phase Equilibria Modelling Method. Note: the required tools for each step are indicated by bold text in the input information column on the left hand side; the output information and/or results from each step are highlighted in the column on the right hand side. 
Data Organisation

Algorithm (A)
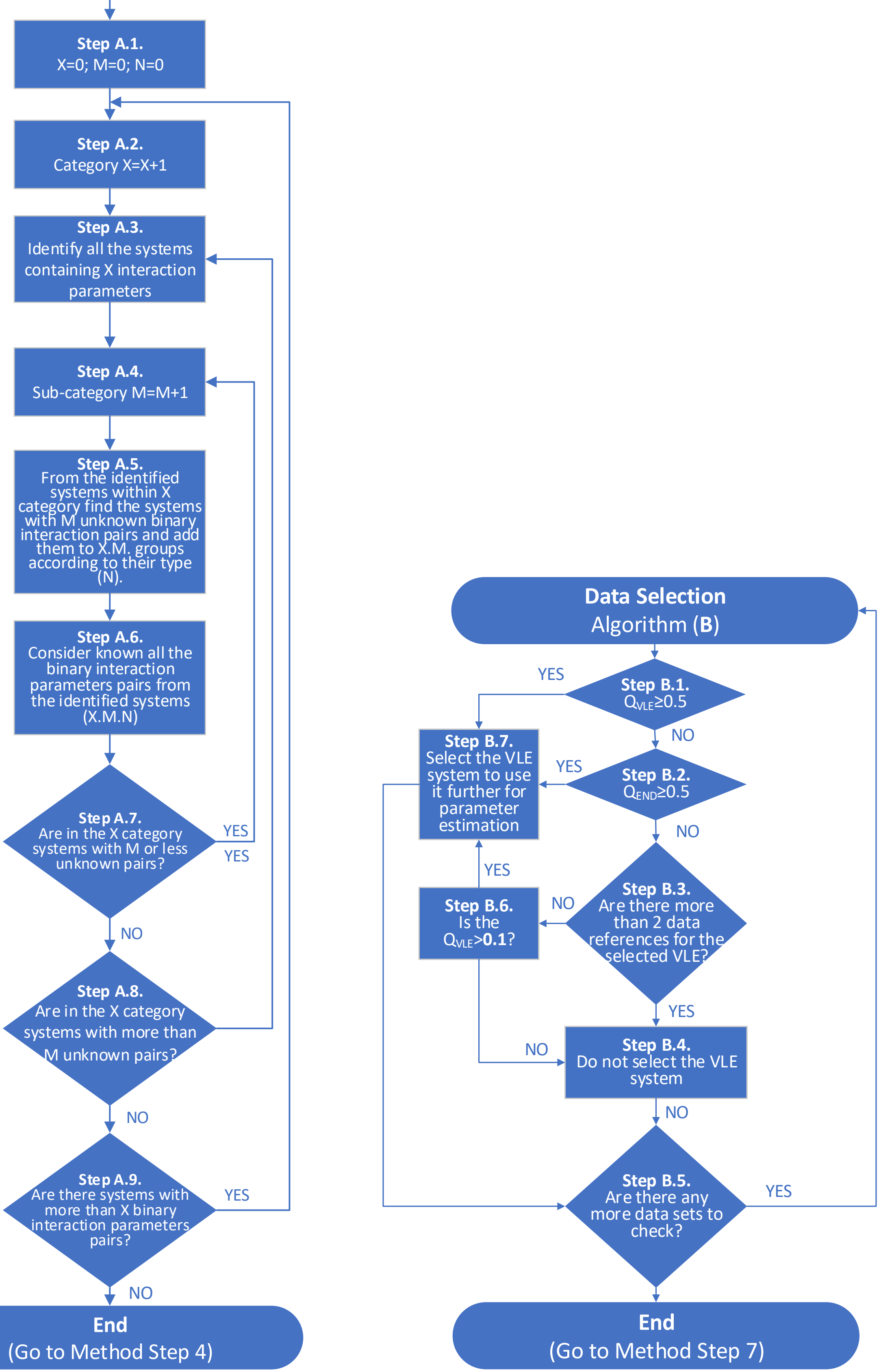

Figure 5. Algorithms used with the method for data organisation (Algorithm A) and data selection (Algorithm B). 


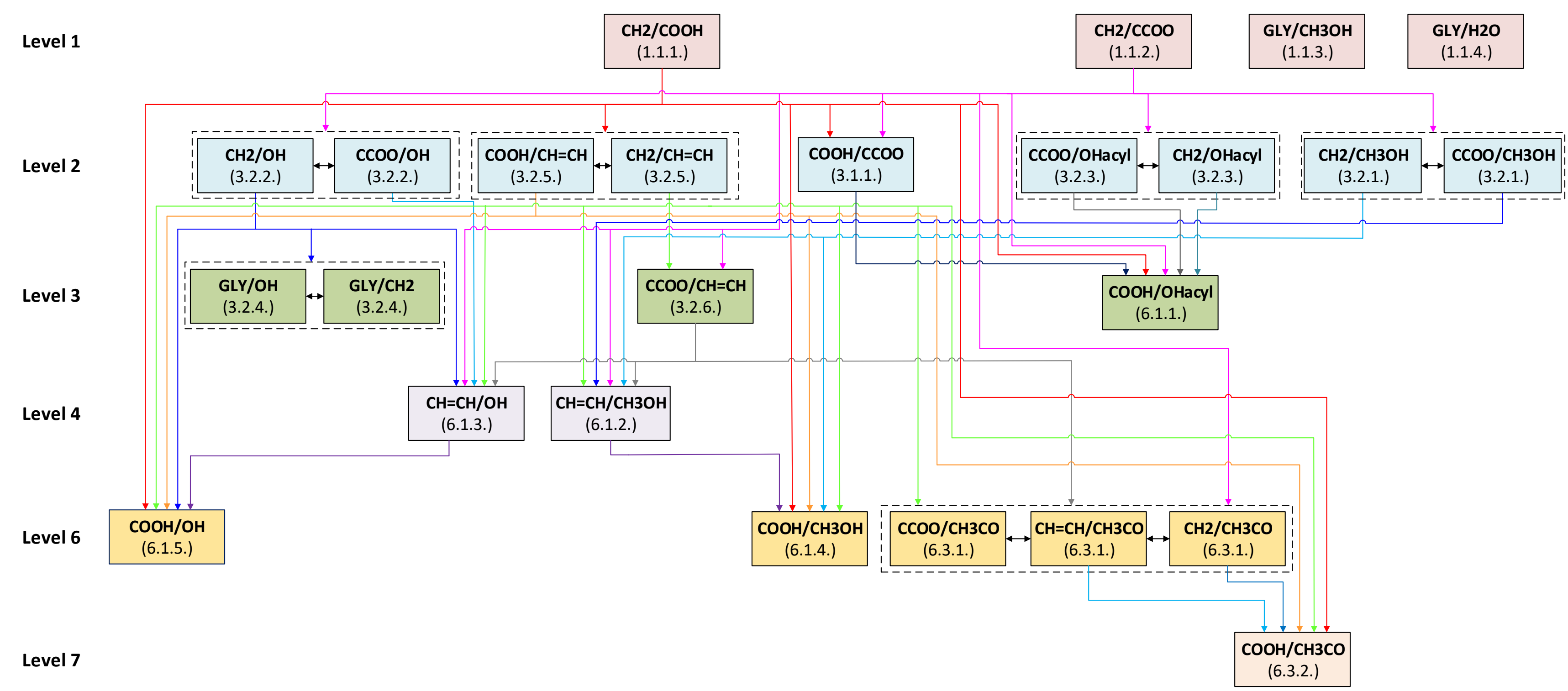

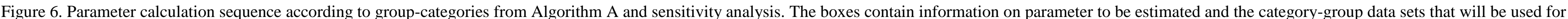
regression; dotted boxes are for the parameters that are estimated from the same category-group data sets. The regression of the parameters is performed from top to bottom and from left to right. 


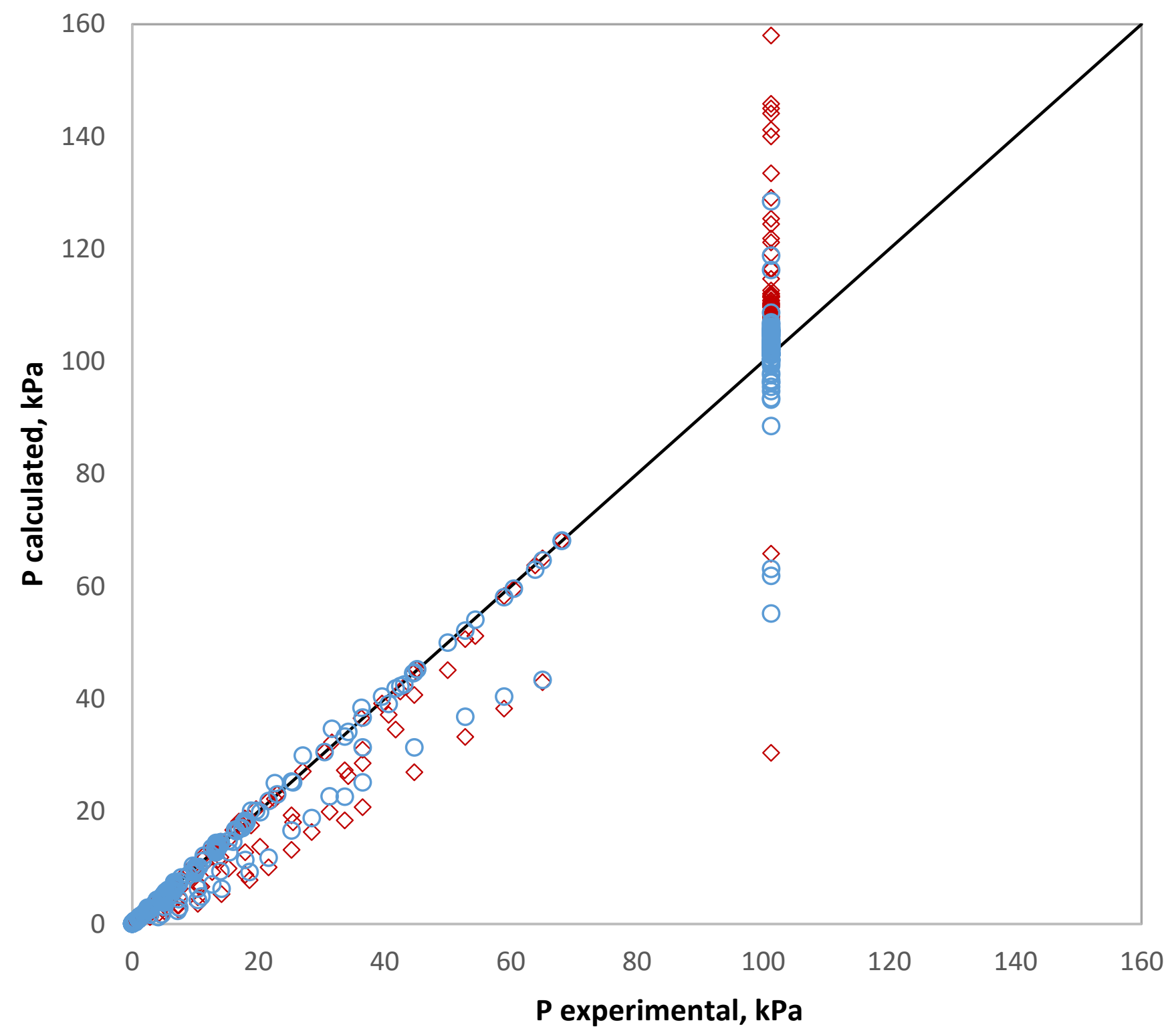

Figure 7. Parity plot of Original UNIFAC prediction using published and lipids based parameters vs. experimental pressure: $\diamond$ Original UNIFAC with published parameters, $\odot$ Original UNIFAC with lipids based parameters. 


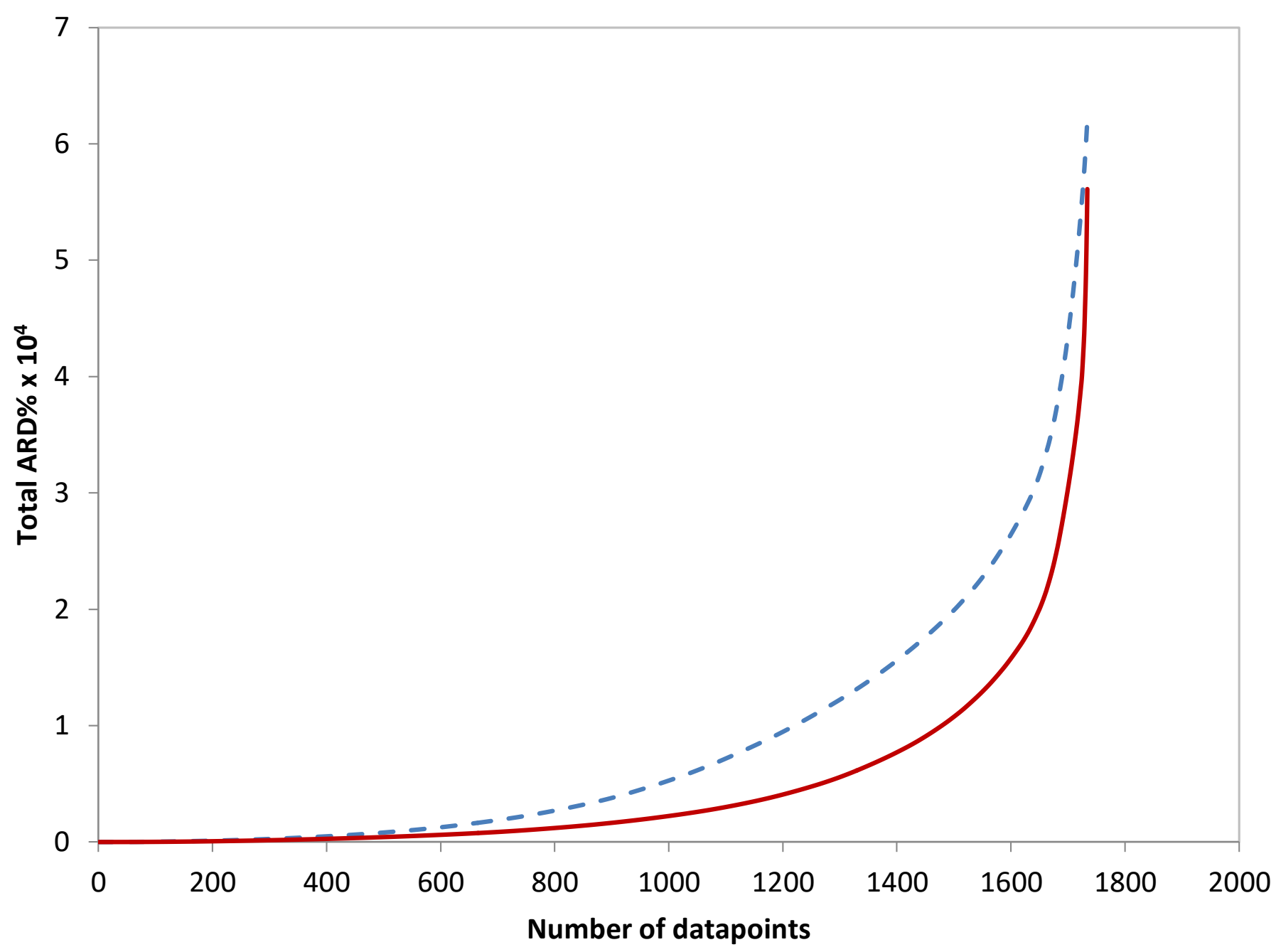

Figure 8. Cumulative ARD\% for VLE prediction using Original UNIFAC model with published and lipids parameters: - - Original UNIFAC with published parameters, - Original UNIFAC with lipids based parameters. 


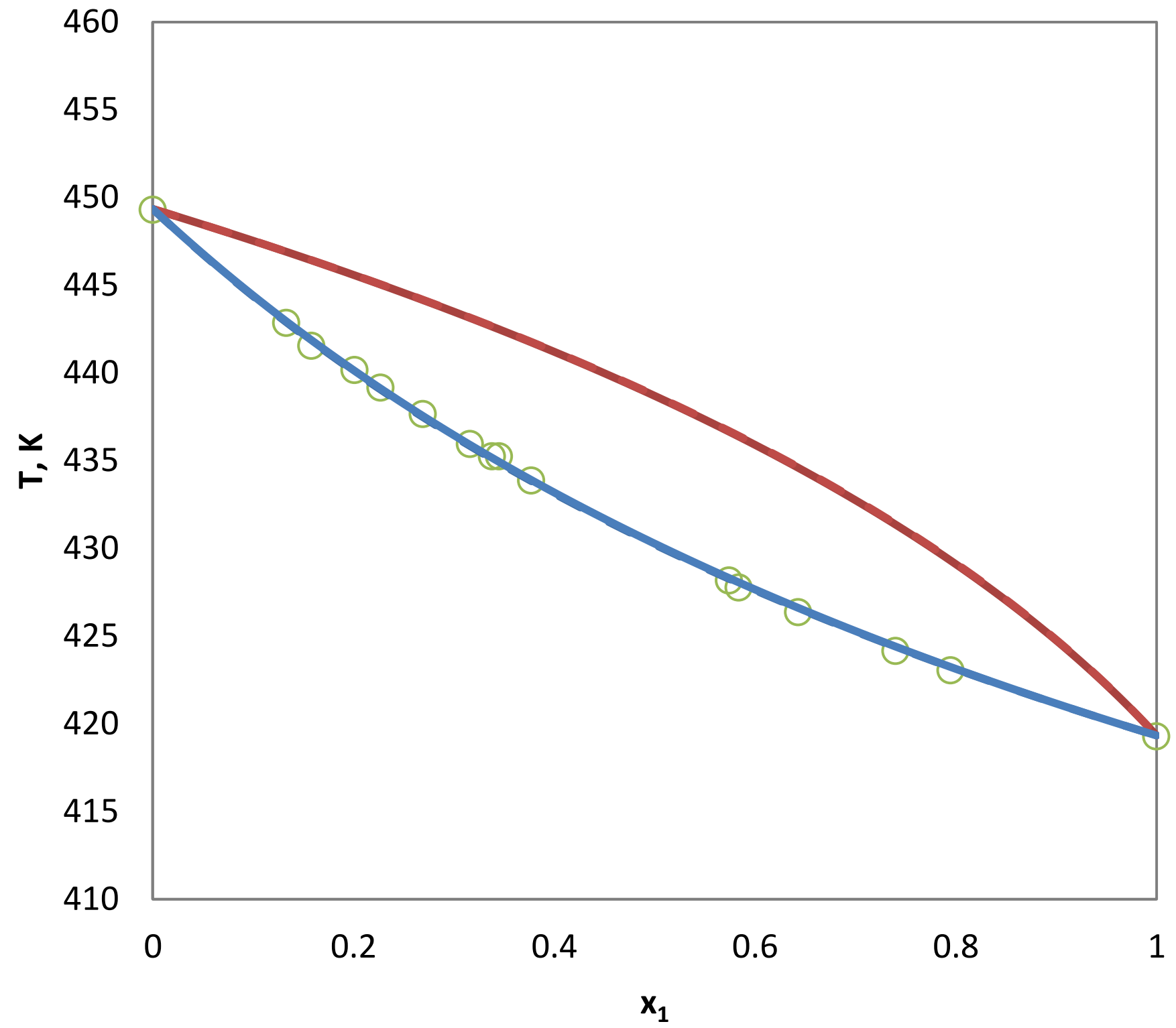

Figure 9. VLE prediction using Original UNIFAC model with published and lipids based parameters for hexanoic acid (1) - octanoic acid (2) systems at $13.33 \mathrm{kPa}$ [67]: $\circ$ experimental data, - - Original UNIFAC with published parameters, - Original UNIFAC with lipids based parameters, red - vapour, blue - liquid. 


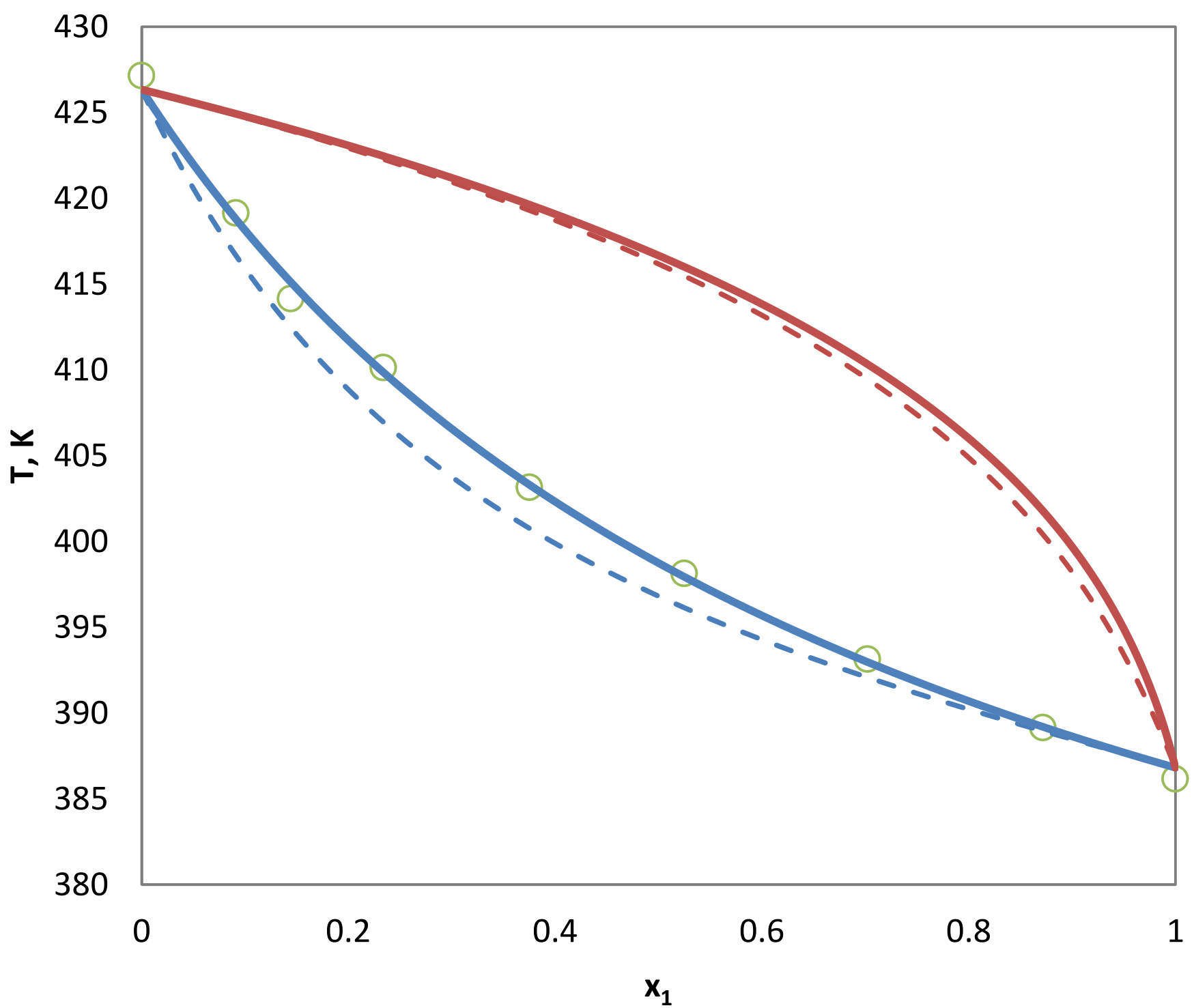

Figure 10. VLE prediction using Original UNIFAC model with published and lipids based parameters for methyl laurate (1) - lauric acid (2) at $0.50 \mathrm{kPa}$ [68]: ○ experimental data, - - Original UNIFAC with published parameters, - Original UNIFAC with lipids based parameters, red vapour, blue - liquid. 


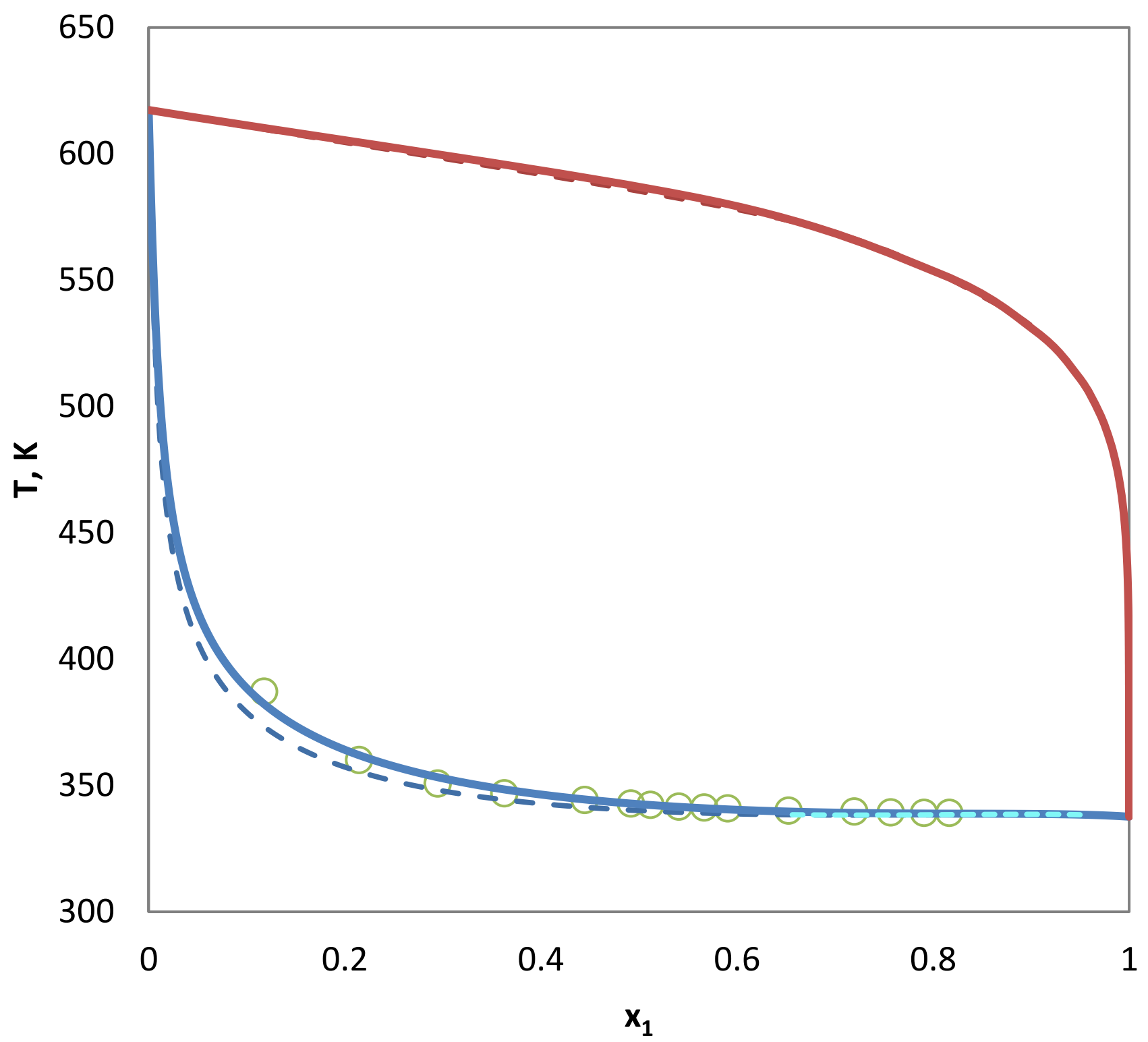

Figure 11. VLE prediction using Original UNIFAC model with published and lipids based parameters for methyl oleate (1) - methanol (2) system at $101.33 \mathrm{kPa}$ [69]: ○ experimental data, - - Original UNIFAC with published parameters, - Original UNIFAC with lipids based parameters, red - vapour, blue - liquid, light blue two phase split. 


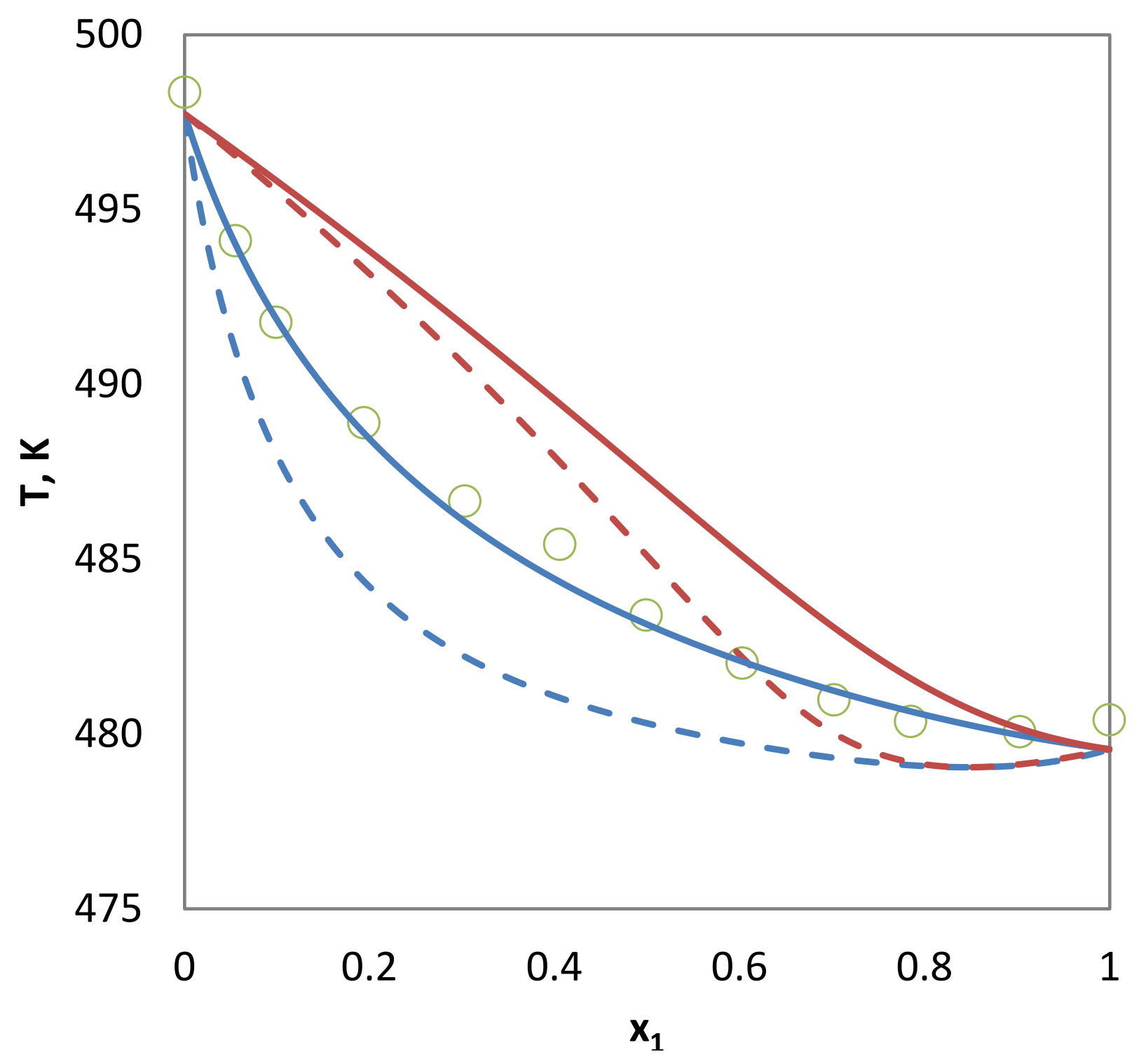

Figure 12. VLE prediction using Original UNIFAC model with published and lipids based parameters for monocaprylin (1) - palmitic acid (2) system at $2.50 \mathrm{kPa}$ [33]: $\circ$ experimental data, - - Original UNIFAC with published parameters, - Original UNIFAC with lipids based parameters, red - vapour, blue - liquid. 


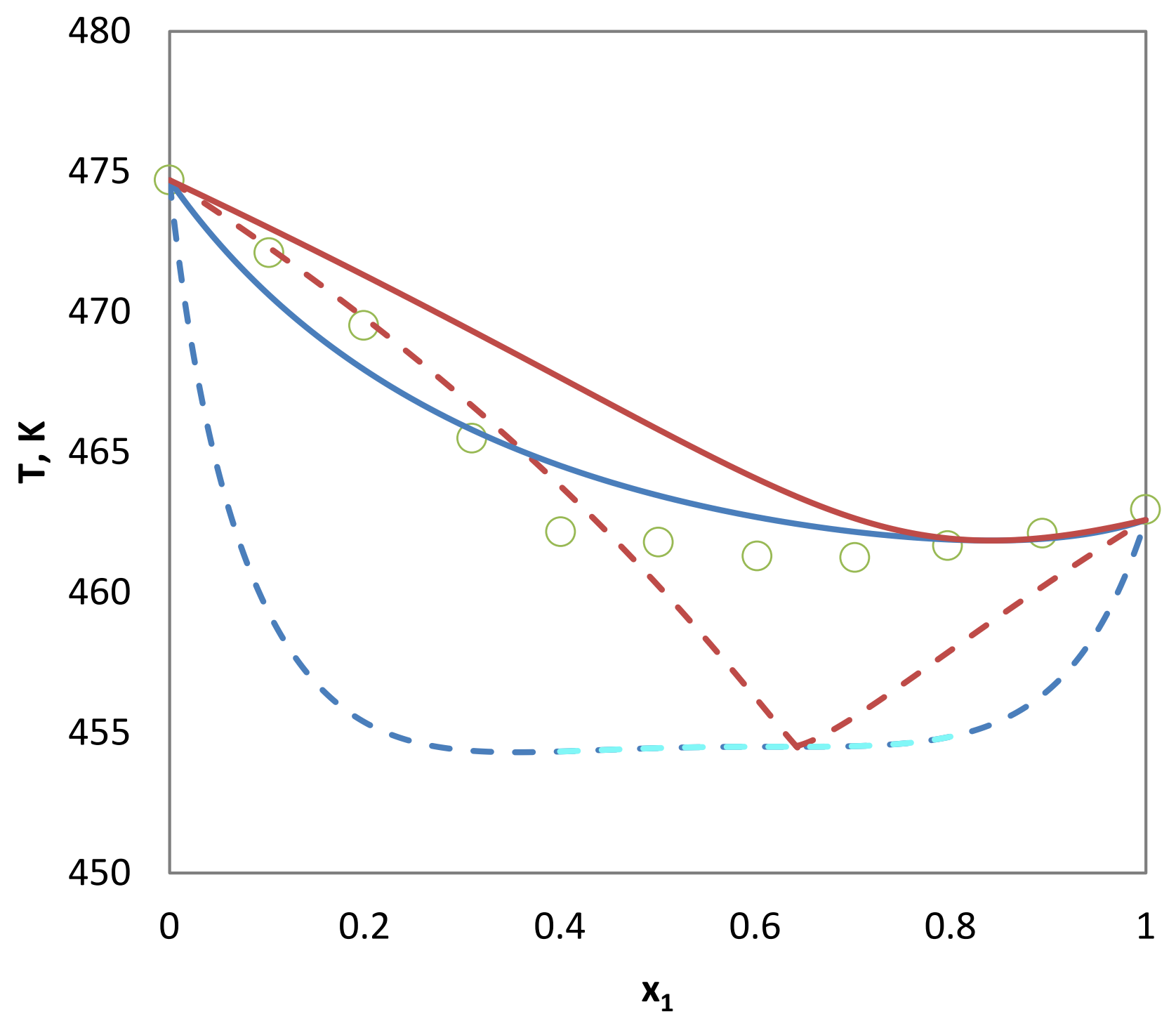

Figure 13. VLE prediction using Original UNIFAC model with published and lipids based parameters for monocaprylin (1) - methyl stearate (2) system at $1.20 \mathrm{kPa}$ [33]: $\circ$ experimental data, - - Original UNIFAC with published parameters, - Original UNIFAC with lipids based parameters, red - vapour, blue - liquid., light blue two phase split. 


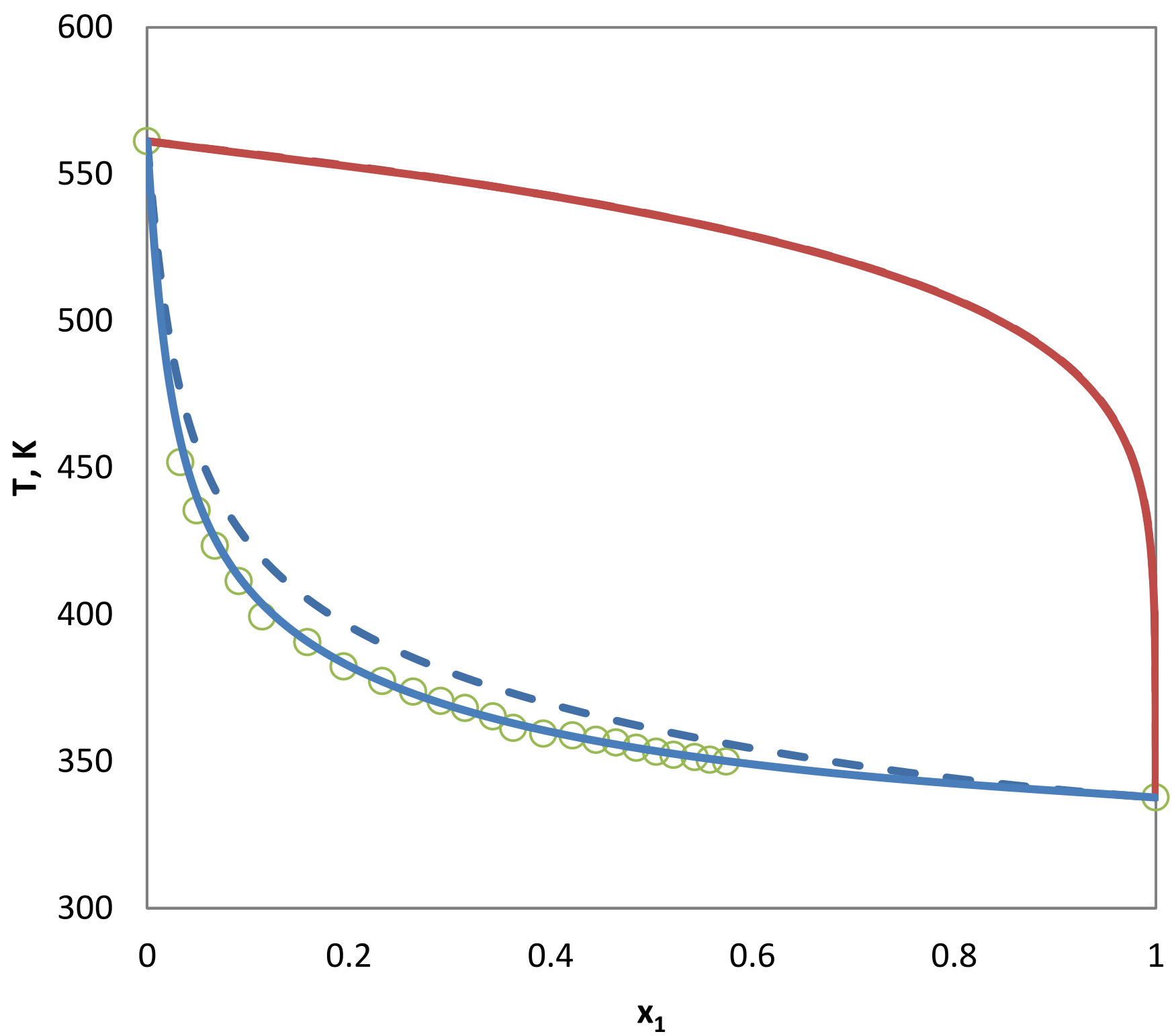

Figure 14. VLE prediction using Original UNIFAC model with published and lipids based parameters for glycerol (1) - methanol (2) system at $101.33 \mathrm{kPa}$ [17]: ० experimental data, - Original UNIFAC with published parameters, - Original UNIFAC with lipids based parameters, red - vapour, blue - liquid. 


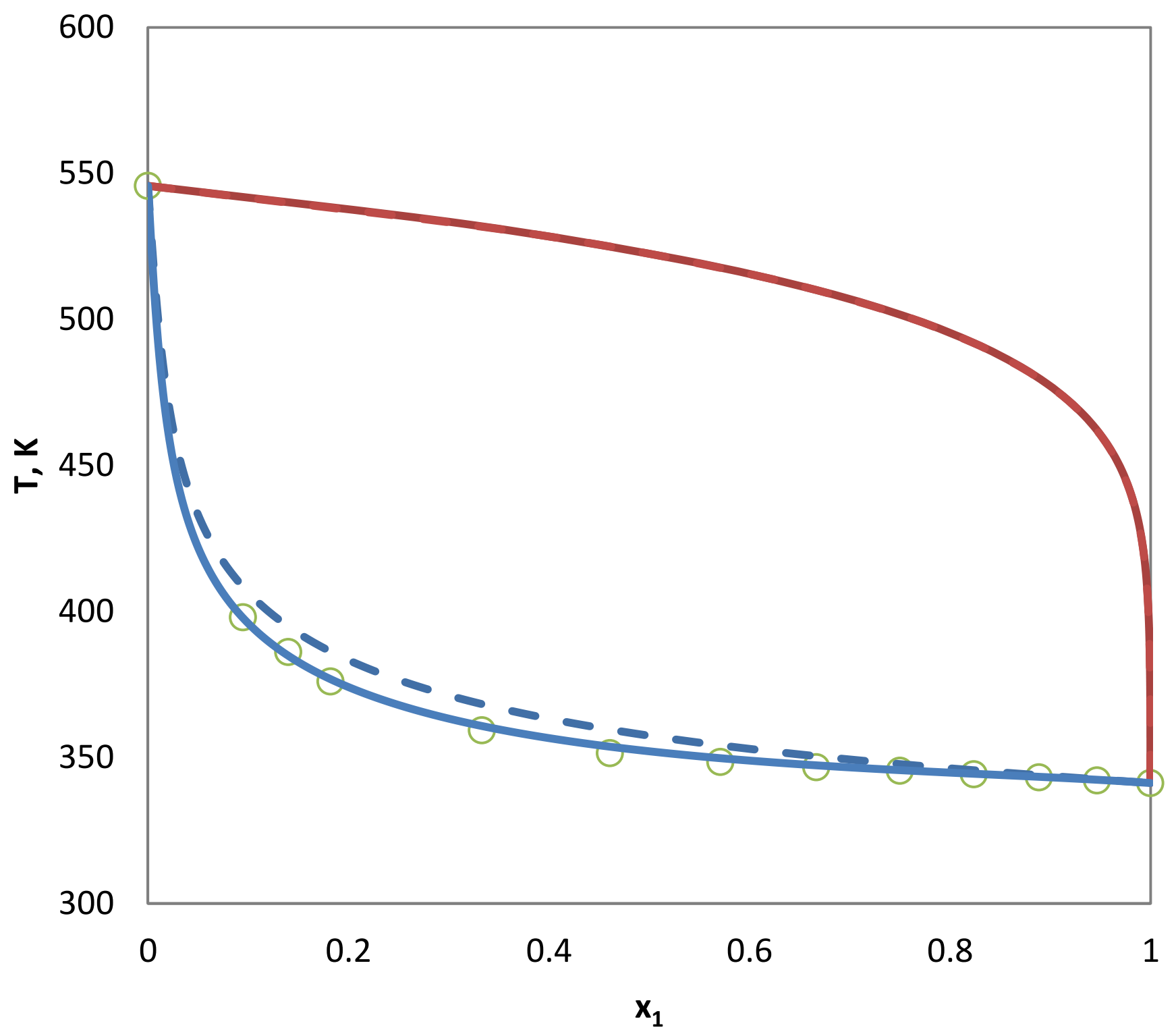

Figure 15. VLE prediction using Original UNIFAC model with published and lipids based parameters for glycerol (1) - ethanol (2) system at $66.70 \mathrm{kPa}$ [72]: ○ experimental data, - - Original UNIFAC with published parameters, - Original UNIFAC with lipids based parameters, red vapour, blue - liquid. 


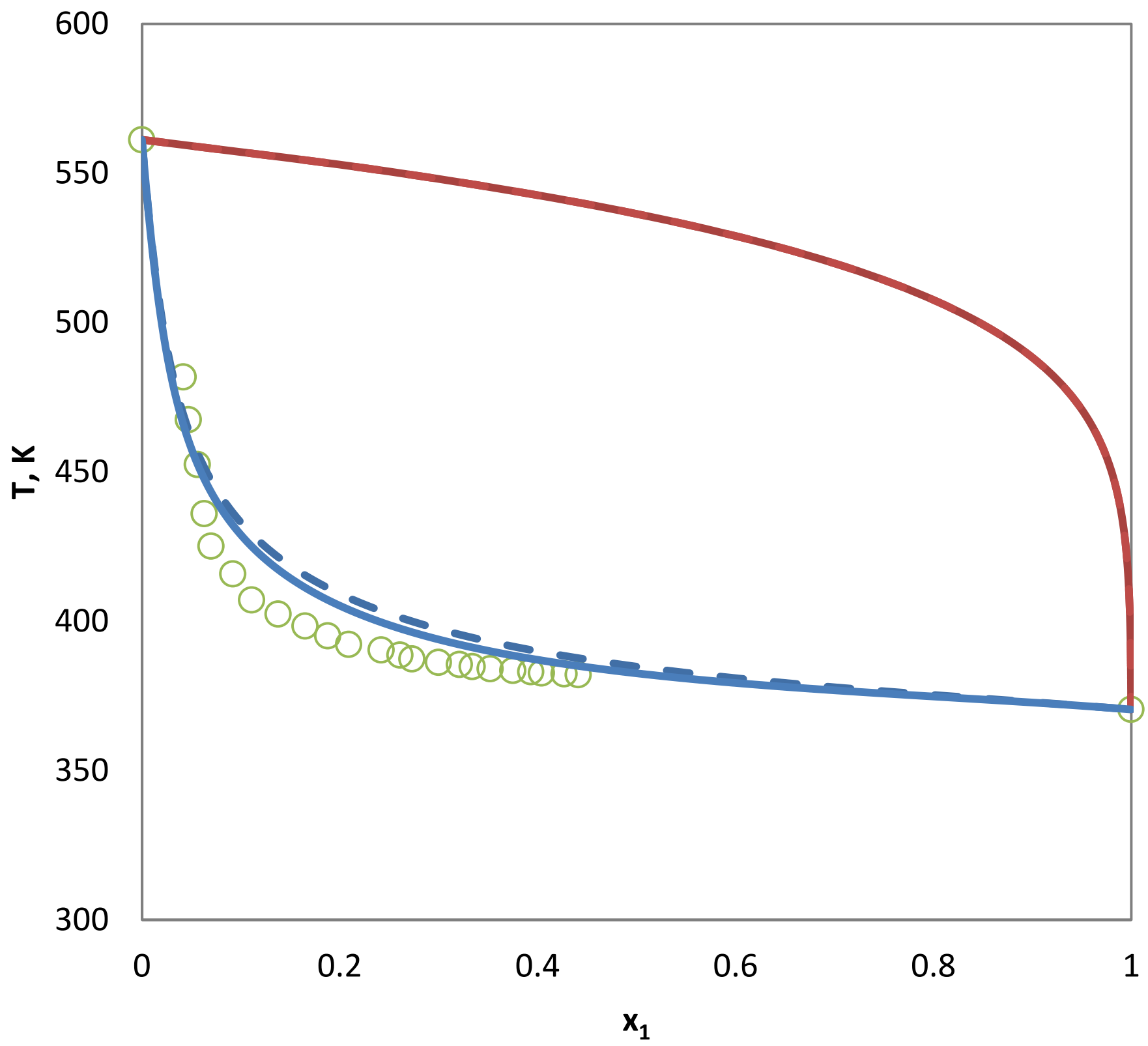

Figure 16. VLE prediction using Original UNIFAC model with published and lipids based parameters for glycerol (1) - 1-propanol (2) system at $101.33 \mathrm{kPa}$ [17]: ० experimental data, - Original UNIFAC with published parameters, - Original UNIFAC with lipids based parameters, red - vapour, blue - liquid. 


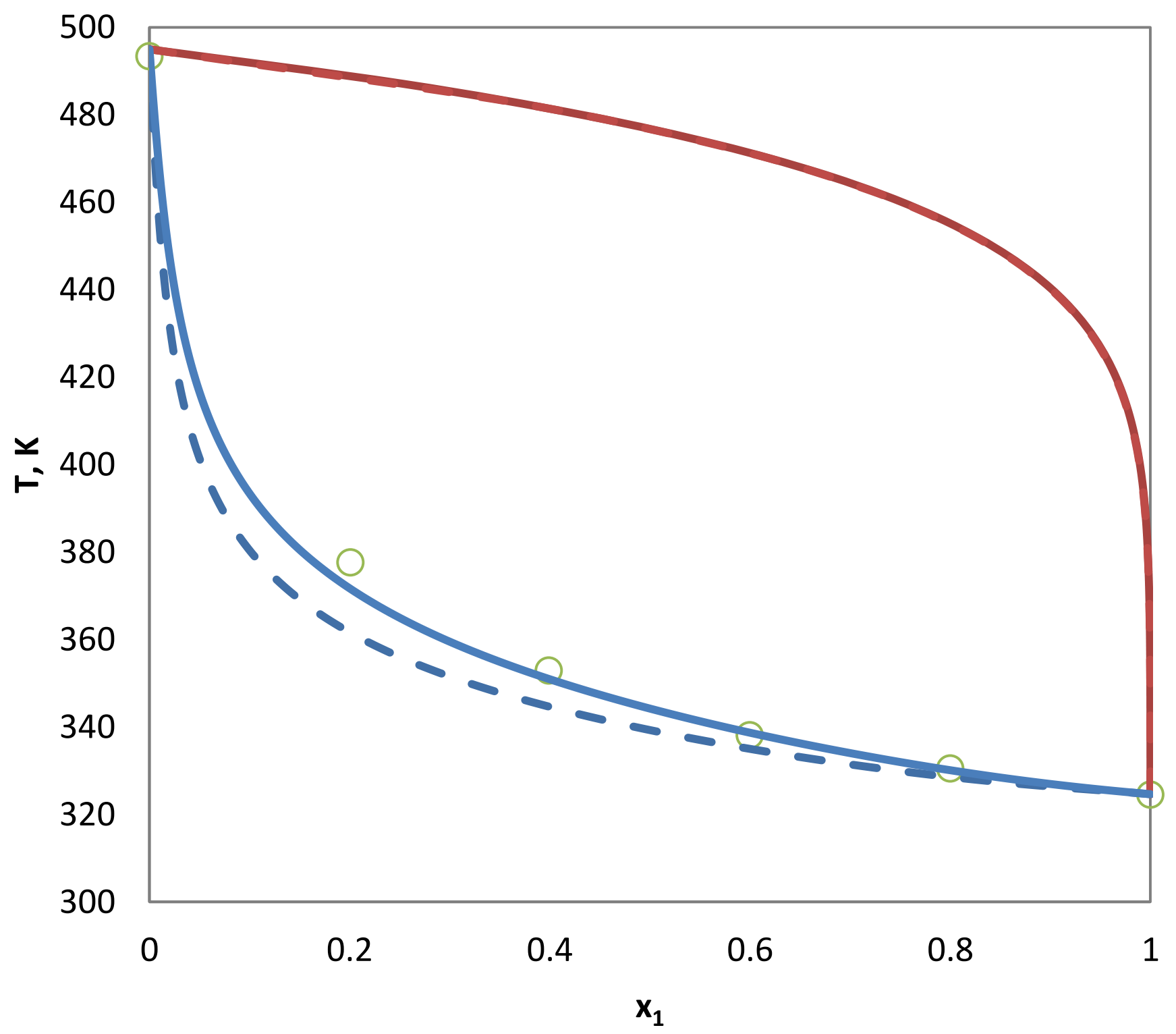

Figure 17. VLE prediction using Original UNIFAC model with published and lipids based parameters for glycerol (1) - water (2) system $66.70 \mathrm{kPa}$ [72]: ० experimental data- - Original UNIFAC with published parameters, - Original UNIFAC with lipids based parameters, red vapour, blue - liquid. 


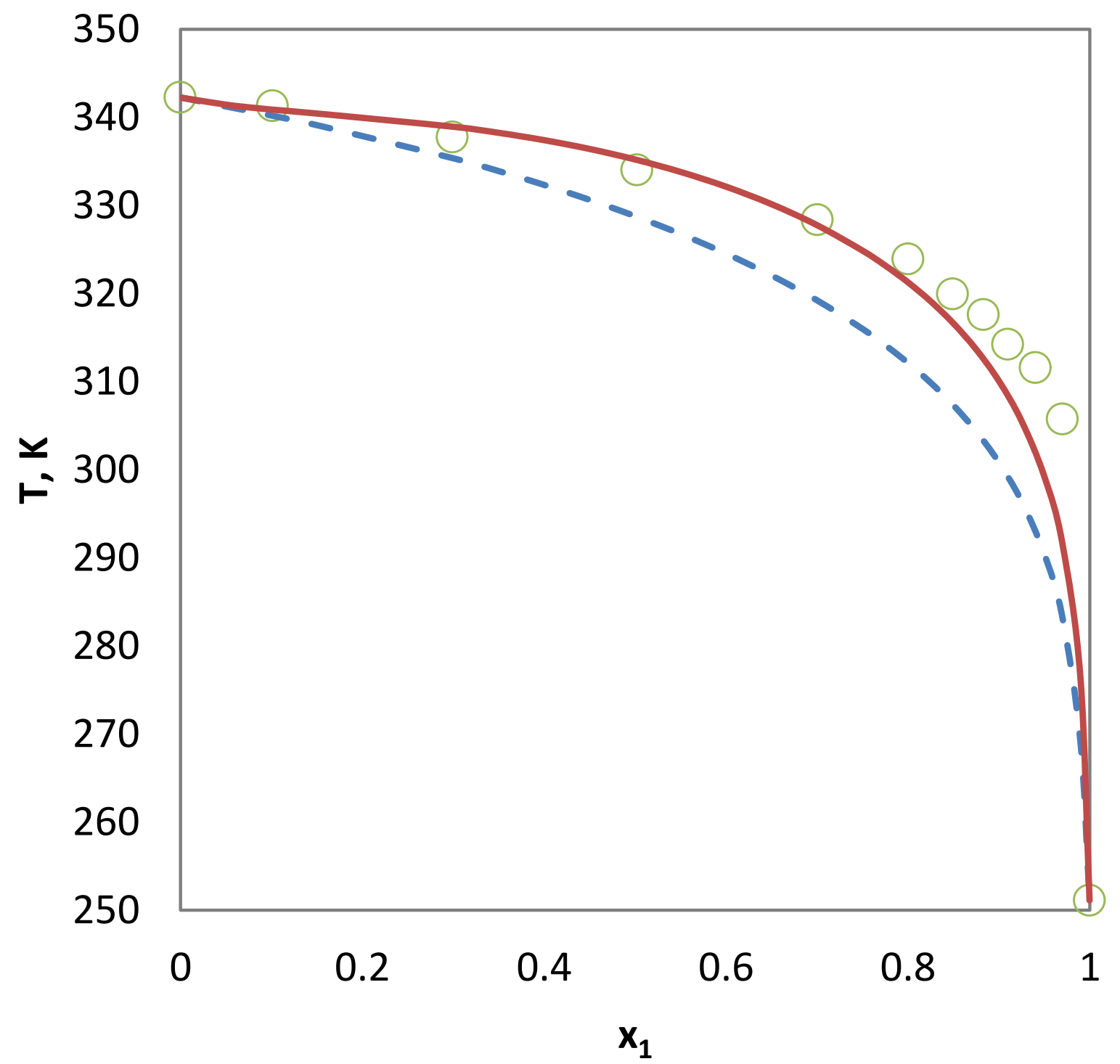

Figure 18. SLE prediction using Original UNIFAC model with published and lipids-based parameters for stearic acid - trilinoleine [73]: $\bigcirc$ experimental data- - Original UNIFAC with published parameters, - Original UNIFAC with lipids based parameters. 


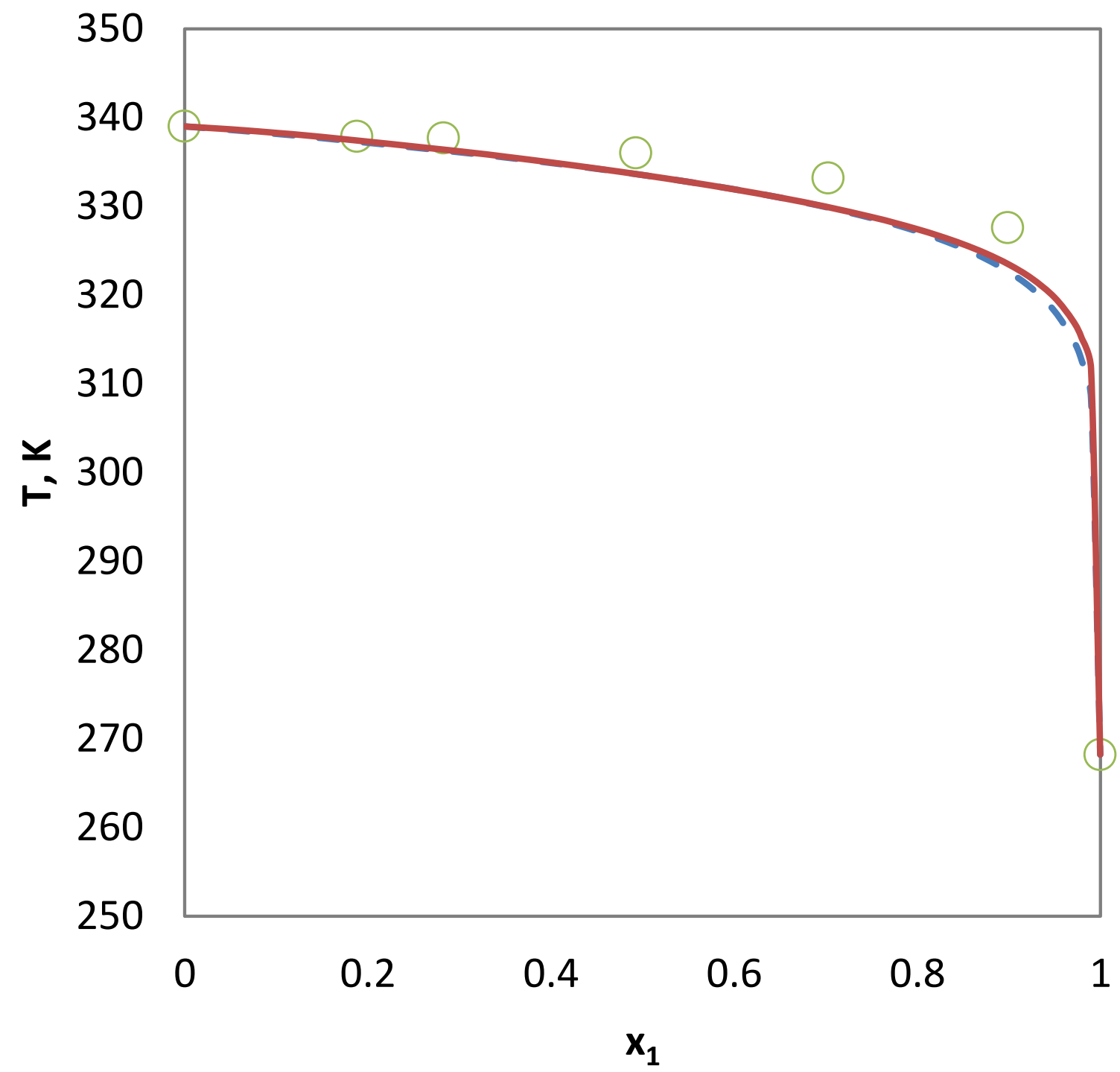

Figure 19. SLE prediction using Original UNIFAC model with published and lipids-based parameters for tripalmitin -linoleic acid [72]: $\circ$ experimental data- - Original UNIFAC with published parameters, - Original UNIFAC with lipids based parameters. 


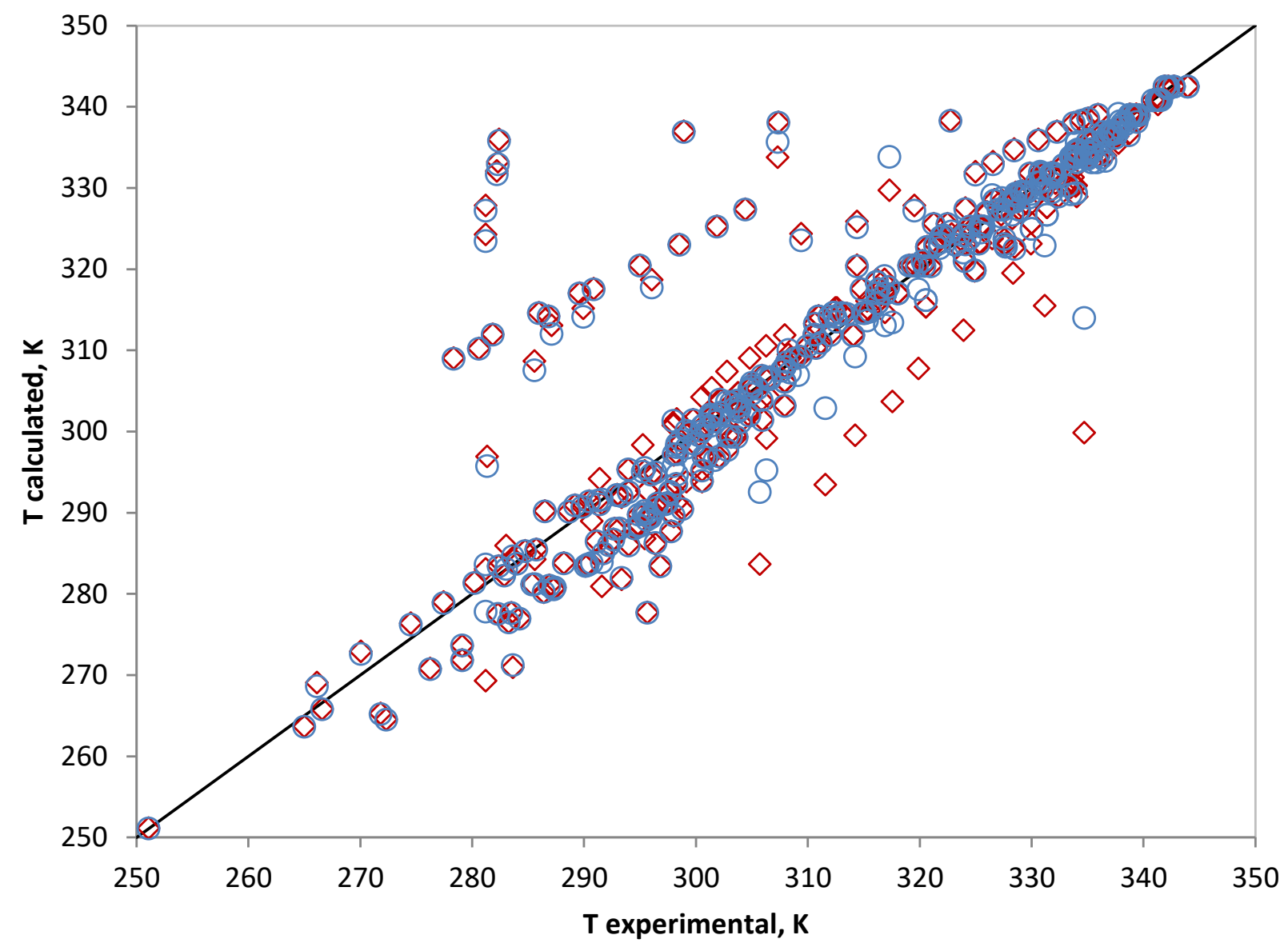

Figure 20. Parity plot for SLE predicted temperature using Original UNIFAC model with published and lipids based parameters vs. experimental temperature: $\diamond$ Original UNIFAC with published parameters, $\bigcirc$ Original UNIFAC with lipids based parameters. 


\section{LIST OF TABLES}

Table 1: List of categories of the lipids for which pure compound data is available in SPEED Lipids Database.

Table 2: List of pure compound properties available in the SPEED Lipids database.

Table 3: List of correlations used in the SPEED Lipids Database for functional properties.

Table 4: List of available phase equilibrium data in the SPEED Lipids Database

Table 5: List of the structural groups and their area $\left(\mathrm{Q}_{\mathrm{m}}\right)$ and volume parameters $\left(\mathrm{R}_{\mathrm{m}}\right)$ used in this paper for adopting the Original UNIFAC model for lipids systems.

Table 6. List of VLE data sets type with corresponding category-groups (Algorithm A) and selected data sets from the total available (Algorithm B).

Table 7 Regressed binary group interaction parameters of the Original UNIFAC model for lipids systems.

Table 8: Average relative deviation, $\operatorname{ARD}(\%)$, for the VLE data sets available in SPEED Lipids Database.

Table 9. Database used for the SLE predictions with Original-UNIFAC model organized according Algorithm A.

Table 10. SLE prediction for Original-UNIFAC Model using published and lipids based parameters

Table 11. Examples of systems that would require VLE measurements. 
Table 1: List of categories of the lipids for which pure compound data is available in SPEED Lipids Database.

\begin{tabular}{lcc}
\hline \multicolumn{1}{c}{ Category } & Number of compounds & $\begin{array}{c}\text { Compounds carbon atom } \\
\text { number range }\end{array}$ \\
\hline Carotenoids & 8 & $\mathrm{C}_{40}$ \\
Diglycerides & 41 & $\mathrm{C}_{14}-\mathrm{C}_{43}$ \\
Ethyl esters & 28 & $\mathrm{C}_{8}-\mathrm{C}_{26}$ \\
Ethylhexyl esters & 9 & $\mathrm{C}_{14}-\mathrm{C}_{26}$ \\
Fatty acids & 29 & $\mathrm{C}_{6}-\mathrm{C}_{24}$ \\
Fatty alcohol & 10 & $\mathrm{C}_{6}-\mathrm{C}_{22}$ \\
Isopropyl esters & 3 & $\mathrm{C}_{19}-\mathrm{C}_{21}$ \\
Methyl esters & 28 & $\mathrm{C}_{7}-\mathrm{C}_{25}$ \\
Monoglycerides & 15 & $\mathrm{C}_{11}-\mathrm{C}_{25}$ \\
Others & 16 & $\mathrm{C}_{41}-\mathrm{C}_{47}$ \\
Pesticides & 14 & $\mathrm{C}_{9}-\mathrm{C}_{20}$ \\
Phospholipids & 14 & $\mathrm{C}_{22}-\mathrm{C}_{41}$ \\
Sterol-esters & 7 & $\mathrm{C}_{41}-\mathrm{C}_{47}$ \\
Sterols & 5 & $\mathrm{C}_{27}-\mathrm{C}_{29}$ \\
Triglycerides & 5 & $\mathrm{C}_{27}-\mathrm{C}_{75}$ \\
Triterpenealcohols & $\mathrm{C}_{8}-\mathrm{C}_{30}$ \\
Ubiquinones & $\mathrm{C}_{27}-\mathrm{C}_{29}$ \\
\hline Vitamin E & $\mathrm{C}_{27}-\mathrm{C}_{52}$ \\
\hline
\end{tabular}


Table 2: List of pure compound properties available in the SPEED Lipids database.

\begin{tabular}{lll}
\hline \multicolumn{1}{c}{ Primary properties } & \multicolumn{1}{c}{ Secondary Properties } & \multicolumn{1}{c}{$\begin{array}{c}\text { Functional properties } \\
\text { (Temperature dependent) }\end{array}$} \\
\hline Melting Temperature & Compressibility factor & Vapour Pressure \\
Boiling Temperature & Acentric factor & Liquid Density \\
Critical Temperature & Specific gravity at 289 K & Liquid Viscosity \\
Critical Pressure & Molar volume at 298 K & Surface Tension \\
Critical Volume & Solubility parameter at 298 K & Liquid Thermal \\
& & Conductivity \\
Formation Enthalpy & & Liquid Enthalpy \\
Formation Gibbs & & Ideal Enthalpy \\
Enthalpy & & \\
Molecular weight & & Vaporization Enthalpy \\
Compressibility factor & & Vapour Viscosity \\
Fusion Enthalpy & Vapour Thermal \\
Liquid volume at 298 K & Conductivity \\
Dipole moment & & \\
\hline Acentric Factor & & \\
\hline
\end{tabular}


Table 3: List of correlations used in the SPEED Lipids Database for functional properties.

\begin{tabular}{ll}
\hline Property & Correlation \\
\hline $\begin{array}{l}\text { Vapour Pressure, liquid } \\
\text { viscosity }\end{array}$ & $\ln (\operatorname{Prop})=C_{1}+\frac{C_{2}}{T}+C_{3} \ln T+C_{4} T^{C_{5}}+C_{6} T^{3}+C_{7} T^{6}+\frac{C_{8}}{T^{2}}+\frac{C_{9}}{T^{4}}+C_{10} T^{2}$ \\
$\begin{array}{l}\text { Liquid Enthalpy, Liquid } \\
\text { Density, Liquid Thermal } \\
\text { Conductivity, Surface } \\
\begin{array}{l}\text { Tension, Ideal Enthalpy, } \\
\text { Vapour viscosity }\end{array}\end{array}$ \\
\\
$\begin{array}{l}\text { Vaporisation enthalpy }=\sum_{i=1}^{n} C_{i} T^{i-1} \\
\text { Vapour Thermal Conductivity }\end{array}$ & $\operatorname{Prop}=C_{1} T^{C_{2}} /\left(1+C_{3} / T+C_{4} / T^{2}\right)$ \\
\hline
\end{tabular}


Table 4: List of available phase equilibrium data sets in the SPEED Lipids Database.

\begin{tabular}{lcccc}
\hline \multirow{2}{*}{ Phase Equilibrium Type } & \multicolumn{2}{c}{ Binary } & \multicolumn{2}{c}{ Multicomponent } \\
\cline { 2 - 5 } & Data sets & Data points & Data sets & Data points \\
\hline \multirow{2}{*}{ VLE } & 174 & 1786 & 12 & 64 \\
SLE & 86 & 929 & 22 & 335 \\
LLE & 12 & 187 & 368 & 2893 \\
VLLE & - & - & 7 & 72
\end{tabular}

* Data set refers to the collection of data points for a system of two or more compounds measured at the same conditions and by the same authors. 
Table 5: List of the structural groups and their area $\left(\mathrm{Q}_{\mathrm{m}}\right)$ and volume parameters $\left(\mathrm{R}_{\mathrm{m}}\right)$ used in this paper for adopting the Original UNIFAC model for lipids systems.

\begin{tabular}{|c|c|c|c|}
\hline Main Group & Sub group & $\mathrm{Q}_{\mathrm{m}}$ & $\mathrm{R}_{\mathrm{m}}$ \\
\hline & $\mathrm{CH}_{3}$ & 0.848 & 0.9011 \\
\hline \multirow[t]{2}{*}{$\mathrm{CH}_{2}$} & $\mathrm{CH}_{2}$ & 0.540 & 0.6744 \\
\hline & $\mathrm{CH}$ & 0.228 & 0.4469 \\
\hline $\mathrm{C}=\mathrm{C}$ & $\mathrm{CH}=\mathrm{CH}$ & 0.867 & 1.1167 \\
\hline $\mathrm{OH}$ & $\mathrm{OH}$ & 1.200 & 1.0000 \\
\hline $\mathrm{CH}_{3} \mathrm{OH}$ & $\mathrm{CH}_{3} \mathrm{OH}$ & 1.432 & 1.4311 \\
\hline $\mathrm{H}_{2} \mathrm{O}$ & $\mathrm{H}_{2} \mathrm{O}$ & 1.400 & 0.9200 \\
\hline $\mathrm{CH}_{3} \mathrm{CO}$ & $\mathrm{CH}_{3} \mathrm{CO}$ & 1.488 & 1.6724 \\
\hline $\mathrm{CCOO}$ & $\mathrm{CH}_{2} \mathrm{COO}$ & 1.420 & 1.6764 \\
\hline $\mathrm{COOH}$ & $\mathrm{COOH}$ & 1.224 & 1.3013 \\
\hline $\mathrm{OH}_{\mathrm{acyl}}^{\mathrm{a}}$ & $\mathrm{OH}_{\mathrm{acyl}}$ & 1.200 & 1.0000 \\
\hline $\mathrm{GLY}^{\mathrm{b}}$ & GLY & 4.908 & 4.7957 \\
\hline
\end{tabular}

${ }^{\mathrm{a}} \mathrm{OH}_{\mathrm{acyl}}$ is a new group describing mono- and diacylglycerols molecules and it uses same $\mathrm{R}$ and $\mathrm{Q}$ as $\mathrm{OH}$ group.

${ }^{\mathrm{b}}$ GLY is a new group describing glycerol molecule. $\mathrm{R}$ and $\mathrm{Q}$ parameters are calculated from contribution of constitutive groups $\left(\mathrm{CH}_{2}, \mathrm{CH}, \mathrm{OH}\right)$. 
Table 6. List of VLE data sets type with corresponding category-groups (Algorithm A) and selected data sets from the total available (Algorithm B).

\begin{tabular}{|c|c|c|c|c|c|c|c|}
\hline \multirow{3}{*}{$\begin{array}{l}\text { Category- } \\
\text { Group } \\
\text { (X.M.N) }\end{array}$} & & & \multirow{3}{*}{ Associated groups } & \multicolumn{4}{|c|}{ VLE data } \\
\hline & \multirow{2}{*}{\multicolumn{2}{|c|}{ System Type }} & & \multicolumn{2}{|c|}{ Available } & \multicolumn{2}{|c|}{ Selected } \\
\hline & & & & Data & Data & Data & Data \\
\hline 1.1 .1 & Saturated Fatty acid & Saturated Fatty acid & $\mathrm{CH}_{2} \mathrm{COOH}$ & 23 & 226 & 4 & 58 \\
\hline 1.1.2. & $\begin{array}{l}\text { Saturated Ester } \\
\text { Saturated Ester }\end{array}$ & $\begin{array}{l}\text { Saturated Ester } \\
\text { Saturated Hydrocarbon }\end{array}$ & $\mathrm{CH}_{2} \mathrm{CCOO}$ & 26 & 246 & 9 & 80 \\
\hline 1.1.3. & Glycerol & Methanol & $\mathrm{GLY} \mathrm{CH} \mathrm{CH}_{3} \mathrm{OH}$ & 20 & 196 & 9 & 118 \\
\hline 1.1.4. & Glycerol & Water & GLY $\mathrm{H}_{2} \mathrm{O}$ & 44 & 468 & 14 & 165 \\
\hline 3.1.1. & Saturated Fatty acid & Saturated Ester & $\mathrm{CH}_{2} \mathrm{COOH} \mathrm{CCOO}$ & 1 & 8 & 1 & 8 \\
\hline 3.2.1. & Saturated Ester & Methanol & $\mathrm{CH}_{2} \mathrm{CH}_{3} \mathrm{OH} \mathrm{CCOO}$ & 5 & 58 & 5 & 58 \\
\hline 3.2.2. & Saturated Ester & Ethanol & $\mathrm{CH}_{2} \mathrm{OH} \mathrm{CCOO}$ & 2 & 36 & 2 & 36 \\
\hline 3.2.3. & $\begin{array}{l}\text { Saturated } \\
\text { Monoglyceride }\end{array}$ & Saturated Ester & $\mathrm{CH}_{2} \mathrm{OH}_{\mathrm{acyl}} \mathrm{CCOO}$ & 2 & 22 & 2 & 22 \\
\hline 3.2 .4 . & Glycerol & Saturated Alcohol & $\mathrm{CH}_{2} \mathrm{OH}$ GLY & 34 & 390 & 11 & 146 \\
\hline & $\begin{array}{l}\text { Unsaturated Fatty } \\
\text { acid }\end{array}$ & Saturated Fatty acid & & & & & \\
\hline 3.2.5. & $\begin{array}{l}\text { Unsaturated Fatty } \\
\text { acid }\end{array}$ & Saturated Hydrocarbon & $\mathrm{CH}_{2} \mathrm{COOH} \mathrm{CH}=\mathrm{CH}$ & 3 & 35 & 1 & 14 \\
\hline 3.2.6. & $\begin{array}{l}\text { Unsaturated } \\
\text { Triglyceride }\end{array}$ & Saturated Hydrocarbon & $\begin{array}{l}\mathrm{CH}_{2} \mathrm{CH}=\mathrm{CH} \\
\mathrm{CCOO}\end{array}$ & 3 & 31 & 2 & 22 \\
\hline 6.1.1. & $\begin{array}{l}\text { Saturated } \\
\text { Monoglyceride }\end{array}$ & Saturated Fatty acid & $\begin{array}{l}\mathrm{CH}_{2} \mathrm{OH}_{\mathrm{acyl}} \mathrm{CCOO} \\
\mathrm{COOH}\end{array}$ & 2 & 24 & 2 & 24 \\
\hline
\end{tabular}


6.1.2. Unsaturated Ester Methanol

6.1.3. Unsaturated Ester Ethanol

6.1.4. Unsaturated Fatty Methanol
acid

6.1.5. Saturated Fatty acid Saturated Alcohol

$\begin{array}{ll}\text { 6.3.1. } & \text { Unsaturated } \\ \text { Triglyceride } & \text { Acetone }\end{array}$

6.3.2. Saturated Fatty acid Acetone
$\mathrm{CH}_{2} \mathrm{CH}=\mathrm{CH}$

$\mathrm{CH}_{3} \mathrm{OH} \mathrm{CCOO}$

$\mathrm{CH}_{2} \mathrm{CH}=\mathrm{CH} \mathrm{OH}$

$\mathrm{CCOO}$

$\mathrm{CH}_{2} \mathrm{COOH} \mathrm{CH}=\mathrm{CH}$

$\mathrm{CH}_{3} \mathrm{OH}$

$\mathrm{CH}_{2} \mathrm{CH}=\mathrm{CH} \mathrm{OH}$

$\mathrm{COOH}$

$\mathrm{CH}_{2} \mathrm{CH}=\mathrm{CH}$

$\mathrm{CH}_{2} \mathrm{CO} \mathrm{CCOO}$

$\mathrm{CH}_{2} \mathrm{CH}=\mathrm{CH}$

$\mathrm{CH}_{2} \mathrm{CO} \mathrm{COOH}$ $\begin{array}{lll}2 & 31 & 1\end{array}$

15

$2 \quad 26 \quad 2 \quad 26$

$\begin{array}{llll}1 & 14 & 1 & 14\end{array}$

$\begin{array}{llll}2 & 27 & 2 & 27\end{array}$

$\begin{array}{llll}1 & 13 & 1 & 13\end{array}$

$\begin{array}{llll}1 & 13 & 1 & 13\end{array}$

Total 
Table 7 Regressed binary group interaction parameters of the Original UNIFAC model for lipids systems.

\begin{tabular}{|c|c|c|c|c|c|c|c|c|c|c|}
\hline $\mathrm{a}_{\mathrm{mn}}, \mathrm{K}$ & $\mathrm{CH}_{2}$ & $\mathrm{CH}=\mathrm{CH}$ & $\mathrm{OH}$ & $\mathrm{CH}_{3} \mathrm{OH}$ & $\mathrm{H}_{2} \mathrm{O}$ & $\mathrm{CH}_{2} \mathrm{CO}$ & $\mathrm{CCOO}$ & $\mathrm{COOH}$ & GLY & $\mathrm{OH}_{\text {acyl }}$ \\
\hline $\mathrm{CH}_{2}$ & 0 & 125.74 & 613.72 & 515.53 & & 529.15 & 459.02 & 320.95 & 137.56 & 50.30 \\
\hline $\mathrm{CH}=\mathrm{CH}$ & 555.93 & 0 & 384.72 & 1424.55 & & 528.31 & 54.61 & 998.5 & & \\
\hline $\mathrm{OH}$ & 35.84 & 407.71 & 0 & & & & 555.63 & 294.83 & 128.76 & \\
\hline $\mathrm{CH}_{3} \mathrm{OH}$ & 41.86 & 64.65 & & 0 & & & 229.89 & -272.84 & -7.25 & \\
\hline $\mathrm{H}_{2} \mathrm{O}$ & & & & & 0 & & & & 140.77 & \\
\hline $\mathrm{CH}_{2} \mathrm{CO}$ & 13.51 & -153.42 & & & & 0 & 44.62 & 247.02 & & \\
\hline $\mathrm{CCOO}$ & 395.55 & 135.28 & 406.11 & 421.58 & & 778.64 & 0 & 660.6 & & 253.23 \\
\hline & & & & & & & - & & & \\
\hline $\mathrm{COOH}$ & 1337.28 & 1318.5 & 37.73 & 2981.07 & & 39.48 & 256.39 & 0 & & -129.89 \\
\hline GLY & 45.83 & & 120.90 & 159.54 & 138.70 & & & & 0 & \\
\hline $\mathrm{OH}_{\text {acyl }}$ & 499.23 & & & & & & 124.02 & 222.89 & & 0 \\
\hline
\end{tabular}


Table 8: Average relative deviation, $\operatorname{ARD}(\%)$, for the VLE data sets available in SPEED Lipids database.

\begin{tabular}{|c|c|c|}
\hline \multirow[b]{2}{*}{ Category-group (X.M.N) } & \multicolumn{2}{|c|}{$\operatorname{ARD}(\%)^{\mathrm{a}}$} \\
\hline & $\begin{array}{l}\text { Original UNIFAC model with } \\
\text { published parameters }\end{array}$ & $\begin{array}{c}\text { Original UNIFAC model with lipids } \\
\text { based parameters }\end{array}$ \\
\hline 1.1 .1 & 2.67 & 2.63 \\
\hline 1.1.2 & 6.18 & 5.71 \\
\hline 1.1.3 & 20.76 & 12.50 \\
\hline 1.1.4 & 91.50 & 88.50 \\
\hline 3.1 .1 & 24.39 & 1.65 \\
\hline 3.2 .1 & 15.14 & 10.89 \\
\hline 3.2 .2 & 11.69 & 2.58 \\
\hline 3.2 .3 & 11.63 & 5.45 \\
\hline 3.2 .4 & 27.99 & 24.63 \\
\hline 3.2 .5 & 30.76 & 28.56 \\
\hline 3.2 .6 & 17.88 & 15.48 \\
\hline 6.1 .1 & 17.26 & 3.62 \\
\hline 6.1 .2 & 22.25 & 2.94 \\
\hline 6.1 .3 & 33.87 & 32.07 \\
\hline 6.1 .4 & 10.12 & 5.91 \\
\hline 6.1 .5 & 4.68 & 4.07 \\
\hline 6.3 .1 & 21.30 & 1.99 \\
\hline 6.3 .2 & 20.68 & 2.10 \\
\hline $\operatorname{ARD}(\%)^{\mathrm{b}}$ & 21.71 & 13.96 \\
\hline${ }^{\mathrm{a}} A R D(\%)=1 / N \sum_{i=1}^{N} \mid \frac{P^{\text {experimen }}}{P^{\mathrm{e}}}$ & \begin{tabular}{c|c} 
ulated \\
\end{tabular} \mid 100,$N-$ number of data points & \\
\hline
\end{tabular}


Table 9. Database used for the SLE predictions with Original-UNIFAC model organized according Algorithm A.

\begin{tabular}{|c|c|c|c|c|}
\hline $\begin{array}{l}\text { Category-group } \\
\text { (X.M.N) }\end{array}$ & \multicolumn{2}{|c|}{ System type } & Constitutive groups & $\begin{array}{l}\text { SLE data } \\
\text { sets }\end{array}$ \\
\hline 1.1 .1$. & $\begin{array}{l}\text { Saturated Fatty } \\
\text { Acid }\end{array}$ & $\begin{array}{l}\text { Saturated Fatty } \\
\text { Acid }\end{array}$ & $\mathrm{CH}_{2} \mathrm{COOH}$ & 12 \\
\hline 1.1 .2$. & Saturated Ester & Saturated Ester & $\mathrm{CH}_{2} \mathrm{CCOO}$ & 9 \\
\hline 3.2.5. & $\begin{array}{l}\text { Unsaturated Fatty } \\
\text { Acid }\end{array}$ & $\begin{array}{l}\text { Saturated Fatty } \\
\text { Acid }\end{array}$ & $\mathrm{CH}_{2} \mathrm{COOH} \mathrm{CH}=\mathrm{CH}$ & 5 \\
\hline & Unsaturated Ester & Saturated ester & & \\
\hline 3.2.6. & $\begin{array}{l}\text { Saturated } \\
\text { Triacylglycerol }\end{array}$ & $\begin{array}{l}\text { Unsaturated } \\
\text { Triacylglycerol }\end{array}$ & $\mathrm{CH}_{2} \mathrm{CH}=\mathrm{CH} \mathrm{CCOO}$ & 8 \\
\hline 6.3 .2 & $\begin{array}{l}\text { Saturated Fatty } \\
\text { Acid }\end{array}$ & Acetone & $\mathrm{CH}_{2} \mathrm{CH}=\mathrm{CH} \mathrm{CH}{ }_{2} \mathrm{CO} \mathrm{COOH}$ & 1 \\
\hline Other* & $\begin{array}{l}\text { Unsaturated } \\
\text { Triacylglycerol } \\
\text { Saturated } \\
\text { Triacylglycerol }\end{array}$ & $\begin{array}{l}\text { Saturated Fatty } \\
\text { Acid } \\
\text { Unsaturated Fatty } \\
\text { Acid }\end{array}$ & $\mathrm{CH}_{2} \mathrm{CH}=\mathrm{CH} \mathrm{CH}_{2} \mathrm{COO} \mathrm{COOH}$ & 9 \\
\hline Total & & & & 44 \\
\hline
\end{tabular}

*Other category-group contains constitutive groups that were not in any of the VLE identified category-groups 
Table 10. SLE prediction for Original UNIFAC Model using published and lipids based parameters

\begin{tabular}{|c|c|c|}
\hline \multirow{2}{*}{$\begin{array}{l}\text { Category- } \\
\text { Group } \\
\text { (X.M.N) }\end{array}$} & \multicolumn{2}{|c|}{$\operatorname{ARD}(\%)^{\mathrm{a}}$} \\
\hline & $\begin{array}{l}\text { Original UNIFAC model with } \\
\text { published parameters }\end{array}$ & $\begin{array}{c}\text { Original UNIFAC model with lipids } \\
\text { based parameters }\end{array}$ \\
\hline 1.1 .1 & 0.92 & 0.91 \\
\hline 1.1 .2 & 1.16 & 1.15 \\
\hline 3.2 .5 & 0.46 & 0.50 \\
\hline 3.2 .6 & 2.30 & 2.18 \\
\hline 6.3 .2 & 0.44 & 0.05 \\
\hline Other & 1.99 & 1.60 \\
\hline $\operatorname{ARD}(\%)^{\mathrm{b}}$ & 1.20 & 1.07 \\
\hline \multicolumn{3}{|c|}{${ }^{\mathrm{a}} A R D(\%)=1 / N \sum_{i=1}^{N}\left|\frac{T^{\text {experimental }}-T^{\text {calculated }}}{T^{\text {experimental }}}\right| \cdot 100, \mathrm{~N}-$ number of data points } \\
\hline
\end{tabular}


Table 11. Examples of systems that would require VLE measurements

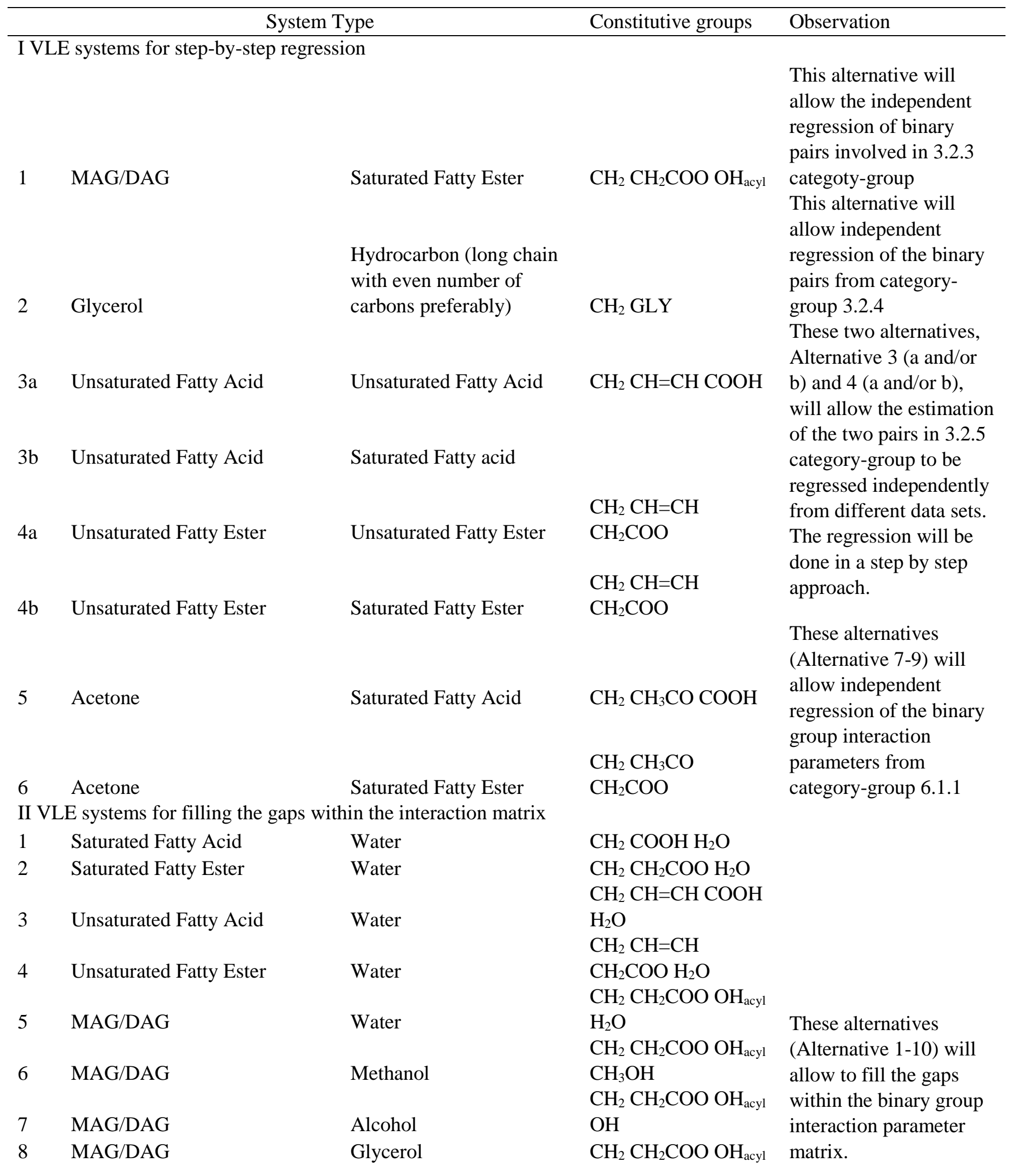




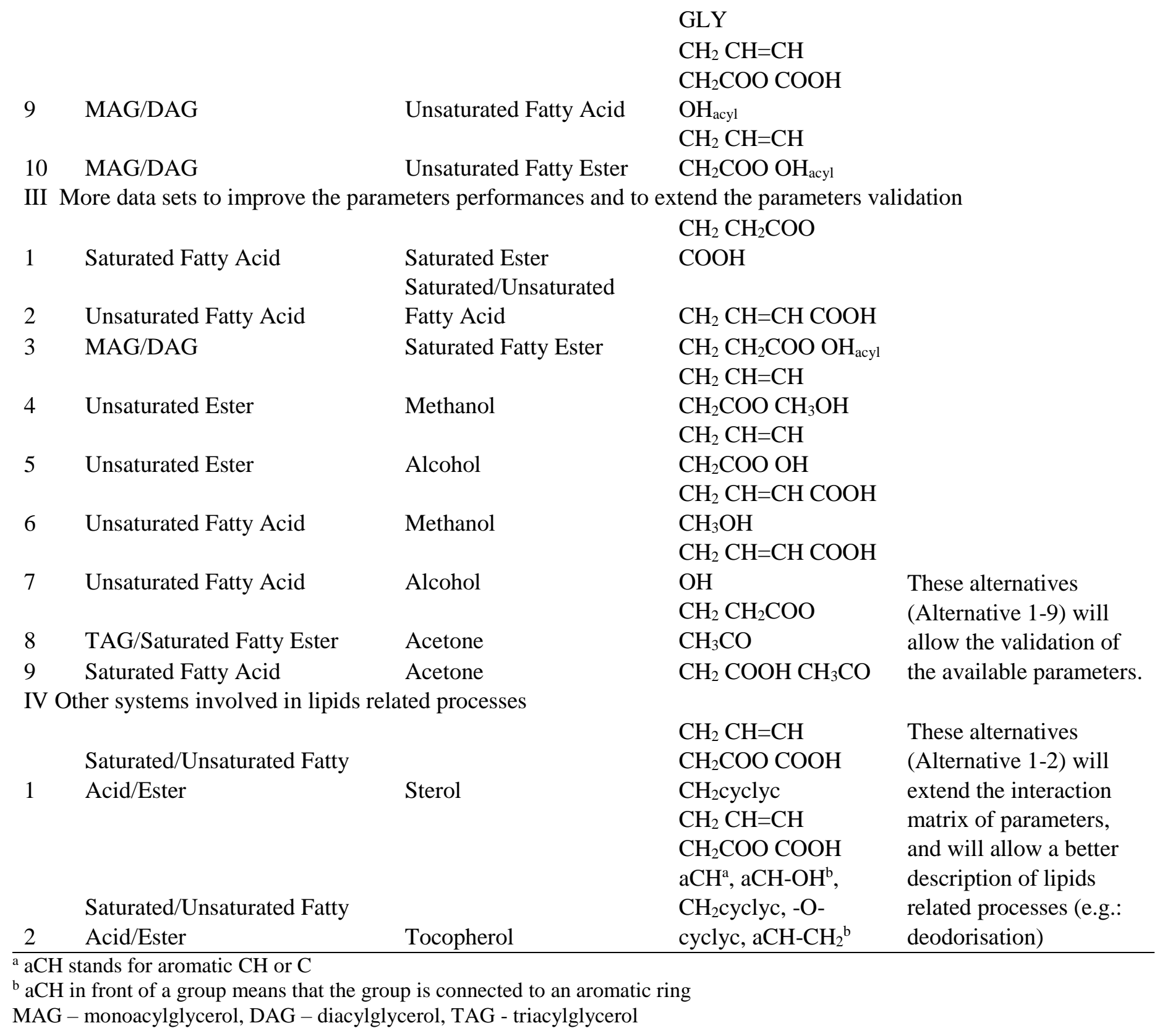

